\title{
Natural attenuation along subsurface flow paths based on modeling and monitoring of a pesticide metabolite from three case studies
}

\author{
Marco Herrmann ${ }^{1 *}$ (10 and Robin Sur ${ }^{2}$
}

\begin{abstract}
Background: Groundwater-especially for the use as drinking water-is a strictly protected resource in the existing guidelines for pesticide registration and drinking water protection in the EU. One aspect that has hardly played a role in this context so far is the attenuation of pesticide concentrations along the flow path from the regulatory leaching concentration at a depth of $1 \mathrm{~m}$ below the applied field to raw water abstraction systems. The soil metabolite $\mathrm{N}, \mathrm{N}$-dimethylsulfamide (DMS) is formed from two fungicidal substances: tolylfluanid and dichlofluanid. According to the EU guidance document on relevant metabolites in groundwater, DMS is a "non-relevant" metabolite. However, long-term application of the two active substances on permanent crops has resulted in elevated and quantifiable amounts of DMS in groundwater catchment areas of water supplying plants. Therefore, in the case of DMS, substantial monitoring data is available. This enables in combination with groundwater modeling, a quantitative analysis of the natural attenuation of DMS concentrations over time and distance. To this end, extensive real-world data from three case studies of drinking water catchment areas in Germany were analyzed.

Results: The environmental fate of DMS in soil and groundwater was evaluated according to the respective data determined at the study sites. Analyses using monitoring data and combined modeling approaches as well, were performed to obtain comparable results. These merged outcomes from monitoring and modeling show total attenuation factors of 12-93 from leachate at $1 \mathrm{~m}$ depth down to monitoring wells-close to raw water collection. If concentration attenuation further downwards to collected raw water is considered, the overall attenuation factor is even higher (40-246).

Conclusions: The conditions at the catchment areas of the three case studies are very diverse, thus providing a wide range of attenuating conditions. When following the path of DMS from its formation in soil below a treated field, to its leaching into the aquifer, and within the aquifer down to the raw water collection site, its concentration in water is continuously and consistently decreasing. The results from DMS represent conservative estimations due to non-sorptive, quick transport processes. Extended to other sorptive solutes, it represents the lower end of expected attenuation. Therefore, natural pesticide concentration attenuation processes are suggested for the consideration in regulatory pesticide risk assessments for a more realistic yet still protective evaluation of expected concentrations in raw water.
\end{abstract}

\footnotetext{
*Correspondence: marco.herrmann@rifcon.de

${ }^{1}$ Rifcon GmbH, Efate Modelling, Goldbeckstraße 13, 69493 Hirschberg,

Germany

Full list of author information is available at the end of the article
}

\section{Springer Open}

(c) The Author(s) 2021. This article is licensed under a Creative Commons Attribution 4.0 International License, which permits use, sharing, adaptation, distribution and reproduction in any medium or format, as long as you give appropriate credit to the original author(s) and the source, provide a link to the Creative Commons licence, and indicate if changes were made. The images or other third party material in this article are included in the article's Creative Commons licence, unless indicated otherwise in a credit line to the material. If material is not included in the article's Creative Commons licence and your intended use is not permitted by statutory regulation or exceeds the permitted use, you will need to obtain permission directly from the copyright holder. To view a copy of this licence, visit http://creativeco mmons.org/licenses/by/4.0/. 
Keywords: N,N-Dimethylsulfamide, Attenuation, Drinking water, Groundwater, Pesticides, Risk assessment, Leaching, Environmental fate, Monitoring, Transport modeling

\section{Background}

Substance (generally), its occurrence and aim of the study

The fungicides tolylfluanid and dichlofluanid were withdrawn globally from the crop protection market in 2006, after the discovery of the major soil metabolite N,Ndimethylsulfamide (DMS). DMS itself is a "non-relevant" metabolite (non-genotoxic, non-toxic, non-pesticidal), according to the EU guidance document on relevant metabolites in groundwater [1]. However, during the treatment of raw water in the course of drinking water processing through ozonation, a carcinogenic transformation product may be formed. As much as $30-50 \%$ of DMS can be converted to NDMA (N-nitrosodimethylamine) during raw water ozonation [2, 3]. That means formation of NDMA from DMS happens via a previously unknown chemical reaction, which requires special but not unrealistic conditions.

Both fungicides were mainly used in less extensive crop cultures like pome and stone fruits, vegetables, grapes, strawberries and hops [4], resulting in a significantly local confinement of DMS occurrences. As these crops are mostly permanent crops, a long-term application of certain pesticides is common. Still today, DMS is one of the most frequently analyzed and detected "non-relevant" metabolites in Germany [5-7]. Especially in cases where drinking water catchment areas are affected by DMS loads, even minor substance entries may get a larger relevance for local drinking water management. However, only $2.4 \%$ of groundwater samples exceed the precautionary health orientation value set for drinking water of $1 \mu \mathrm{g} / \mathrm{L}$ in Germany in the years 2013 to 2016 [8]. Further treatment of groundwater to fulfil this drinking water health safety threshold is therefore only required in rare cases, as significant dilution and mixing of DMS from groundwater to abstracted raw water for drinking water production occurs.

The purpose of this study was to quantify the natural attenuation of DMS concentrations over time and distance using modeling as well as monitoring data from realistic case studies of three drinking water catchment areas in Germany. In these areas, catchment management plans supported by model predictions and monitoring data had been previously implemented or are still ongoing. A simulation of the amount of DMS and the course of the transport time and mobility in leachate and groundwater were needed for each case study. To reflect the different conditions at the three drinking water catchment areas, measured DMS concentrations were considered for validation of the individual modeling approaches. The three case studies are separately described in "Methods" section. Compilation and discussion of the overall results are conducted subsequently.

"Natural attenuation" is an approach that has a broad definition. In an operational definition, all types of processes, which can reduce the concentration of a contaminant in water, are considered. This means in case of this study biodegradation as well as natural physical processes that can immobilize the contaminant. Furthermore, dilution and dispersion as processes that do not destroy or immobilize DMS are considered. An attenuation factor is a function that reflects the distance (vertically and horizontally) in soil layers and aquifer, through which the pesticide is moving, the net annual groundwater recharge, the degradation of the pesticide and the soil properties. It also takes into account pesticide retardation, which is affected by bulk density, organic carbon content, sorption and field capacity [9-11]. Since DMS is not adsorbing in soil, it can be assumed, that it behaves like an ideal tracer, what indicates negligible chemical retardation. See "Physico-chemical properties" section for the main relevant substance parameters of DMS.

\section{Physico-chemical properties}

The physico-chemical and environmental properties of DMS and its parent compounds were taken from an endpoint list used in the European pesticide registration process [4] and from internal studies of the former manufacturer.

\section{Parent compounds}

The fungicides tolylfluanid and dichlofluanid exhibit very similar molecular structures. An additional aromatic methyl-group in the tolylfluanid molecule is the only difference (Fig. 1). The degradation in soil of tolylfluanid-and analogously dichlofluanid-into N,N-dimethylsulfamide (DMS) happens very fast.

Due to the short half-lives of the parent compounds and of further precursor molecules of DMS in soil (1-2 days), an instantaneous formation of DMS from tolylfluanid and dichlofluanid after application with a formation fraction of $22 \%$ in soil was assumed in the model PEARL [12] for the leaching calculations in the upper vadose zone. 


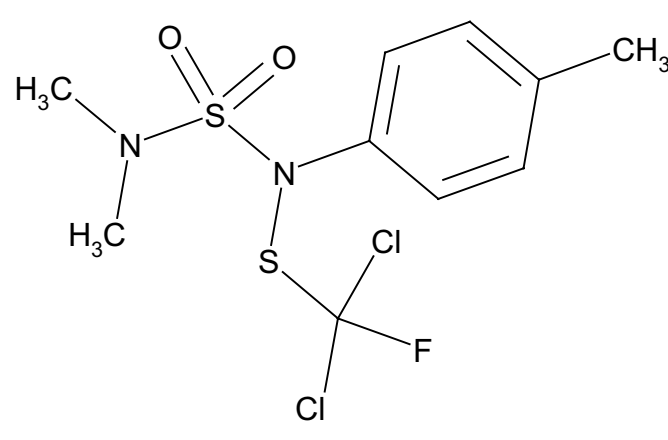

Tolylfluanid

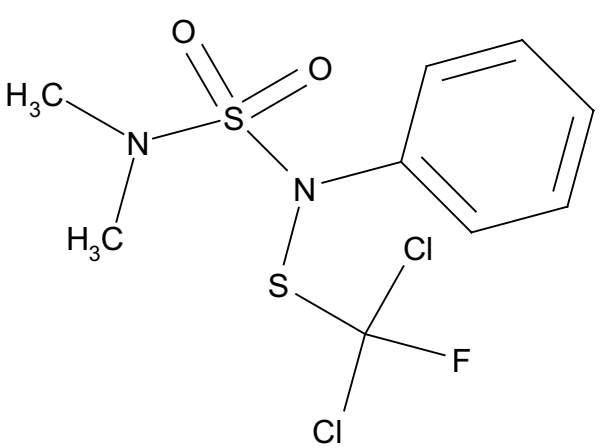

Dichlofluanid

Fig. 1 Molecular structures of tolylfluanid and dichlofluanid

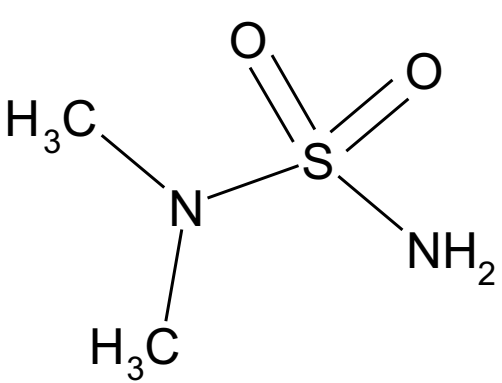

Fig. 2 Molecular structure of $\mathrm{N}, \mathrm{N}$-dimethylsulfamide (DMS)

\section{Dimethylsulfamide (DMS)}

Simulations of the environmental fate of the metabolite DMS (Fig. 2) were performed using substance parameters selected according to recommendations of the FOCUS groups $[13,14]$. Function of the FOCUS groups is to provide the tools and recommend parameter settings for simulating environmental concentrations of plant protection products for the purpose of their evaluation for registration in the EU.

A water solubility of $150 \mathrm{~g} / \mathrm{L}$ at $20^{\circ} \mathrm{C}$, vapor pressure of $1.8 \times 10^{-4} \mathrm{~Pa}$ at $20^{\circ} \mathrm{C}$ and a molar mass of $124.2 \mathrm{~g} / \mathrm{mol}$ were used as modeling parameters describing the molecule. A default plant uptake factor of 0.5 was chosen. As well, as a default according to FOCUS [14], the foliar wash-off was set to zero in accordance with DMS being a soil metabolite.

Furthermore, simulations were carried out using the geometric mean of the first-order $\mathrm{DT}_{50}$ at reference conditions $\left(20^{\circ} \mathrm{C}\right.$ and field capacity) of 127 days (four soils; 36-588 days). This normalized $\mathrm{DT}_{50}$ is based on an unpublished laboratory aerobic soil degradation study on four European soils. Temperature and moisture influence on the degradation rate were considered with the default
Table 1 Compound input parameters for N,N-dimethylsulfamide (DMS)

\begin{tabular}{lll}
\hline Parameter & Unit & DMS \\
\hline Molar mass & $(\mathrm{g} / \mathrm{mol})$ & 124.2 \\
Solubility $\left(20^{\circ} \mathrm{C}\right)$ & $(\mathrm{mg} / \mathrm{L})$ & 150,000 \\
Vapor pressure $\left(20^{\circ} \mathrm{C}\right)$ & $(\mathrm{Pa})$ & $1.8 \times 10^{-4}$ \\
Freundlich exponent & $(-)$ & 0.9 \\
Plant uptake factor & $(-)$ & 0.5 \\
Walker exponent $^{\circ}$ & $(-)$ & 0.7 \\
$\mathrm{DT}_{50}\left(20^{\circ} \mathrm{C} / \mathrm{pF} 2\right)$ & $($ days $)$ & 127 \\
Molar activ. energy ${ }^{\text {a) }}$ & $(\mathrm{JJ} / \mathrm{mol})$ & $54^{\mathrm{b})} / 65.4^{\mathrm{c}}$ \\
Kom & $(\mathrm{mL} / \mathrm{g})$ & 0 \\
\hline
\end{tabular}

${ }^{a}$ Set to predefined standard in the used model version

${ }^{\text {b }}$ Used for Catchment I

' Used for Catchment II \& III

value for the molar activation energy of $54 / 65.4 \mathrm{~kJ} / \mathrm{mol}$ (Arrhenius equation) and the default moisture exponent of 0.7 (Walker equation). For the characterization of the adsorption properties of DMS, an unpublished adsorption/desorption study was conducted in-house on five different European soils. There, soil adsorption was shown to be negligible $\left(K_{\mathrm{OM}}=0 \mathrm{~L} / \mathrm{kg}\right)$. Due to anaerobic conditions and only minor amounts of organic carbon in the saturated zone, no relevant microbial activity on degradation is expected there. For modeling, no degradation of DMS in the aquifer was assumed based on anaerobic soil study data of the manufacturer of tolylfluanid.

Substance parameters used as inputs in the simulations are summarized in Table 1.

\section{Analysis}

All water samples taken after November 2006 were analyzed for DMS by HPLC-MS/MS (TZW, Karlsruhe, Germany, Laborgemeinschaft SüdWest, Langenau, Germany, Labor IWW Mülheim or Bayer CropScience, Monheim, 
Germany). Analysis was conducted after addition of a deuterated internal standard (1,1-dimethylurea-d6-DMS) and by direct injection into an HPLC-MS/MS instrument using electrospray ionization in the positive ionization mode. Two multiple reaction monitoring (MRM) transitions of DMS (m/z 125) were recorded. For quantification, the ion with $\mathrm{m} / \mathrm{z} 108$, and for confirmation, the second MRM transition to the ion with $\mathrm{m} / \mathrm{z} 44$, were evaluated. The limit of quantitation was $\leq 25 \mathrm{ng} / \mathrm{L}$.

Samples from 2005 until November 2006 were not directly analyzed for DMS. Following transformation of DMS to NDMA during ozonation and its analysis by GC-MS, the corresponding maximum available DMS concentration was back calculated [15].

\section{Methods}

Coupled modeling approaches consisting of one-dimensional leaching models (PEARL, HYDRUS-1D) and two- or three-dimensional models for the saturated zone (HYDRUS-2D, FEFLOW) were applied to calculate concentrations of DMS along the flow pathways from treated fields to remote sampling or abstraction sites [16].
For transport modeling within this study, discharge of water via surface runoff was considered negligible for all three sites. This assumption is based on several reasons like application, surface cover and morphology of the catchments. In this context it is relevant, that runoff is generally slowed down by vegetation. The pesticide treatment was performed, according to the usual practice, only on perennial crops and at progressed development stages $(\mathrm{BBCH}>60)$. This means, tolylfluanid and dichlofluanid was applied on ground, which is considerably vegetation covered. This effect is moreover supported by grass, which is mostly growing between the rows of perennial crops like pome-/stone fruits and berries. Between the rows of strawberries, straw is usually interspersed, what is also slowing down or even preventing runoff. And furthermore, the slope is very slight $\left(<1^{\circ}\right)$, at least in cases of Catchment I \& II in the German Rhine plain. At Catchment III the treated field has a slightly higher slope of $1.5^{\circ}$. However, for this slope in combination with the described surface cover of the field and rows, which were laid out across the slope, runoff was also deemed neglectable.

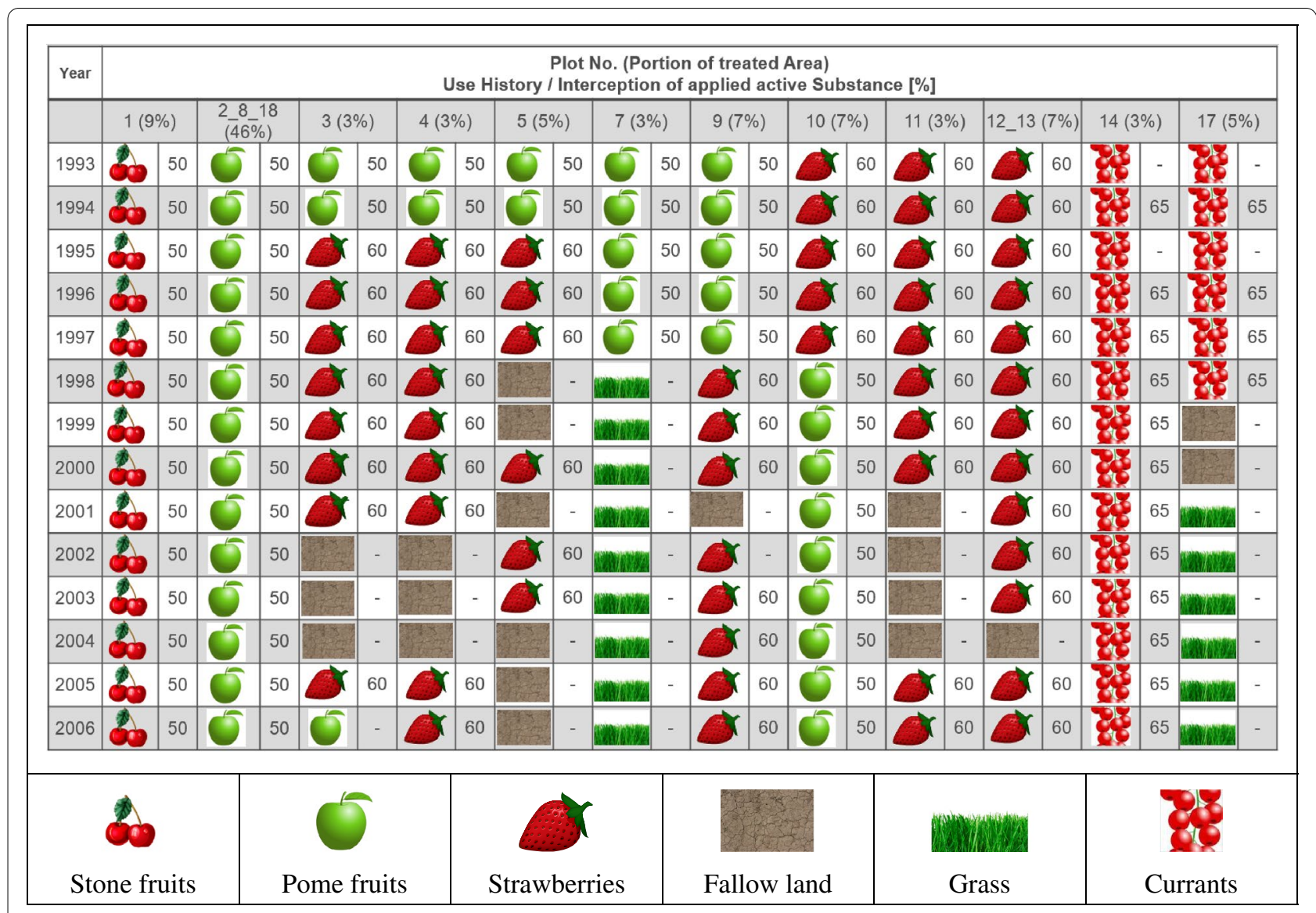

Fig. 3 Use history of 18 plots at the orchard (Plots 6, 15, 16 were not treated with active substance) 
Macroporous transfer was not considered separately in this study. The calculation of matrix flow only, was assumed to be sufficiently accurate. This is reasoned by the compound properties of DMS (high solubility, nonsorbing, slow degradation). Since this, it is indicated that single macroporous flow events are probably not of high importance at the considered depths and over long term.

\section{Description of case studies and applied methods Case study of Catchment I-Rhein-Ruhr Region}

A 14.4-ha-sized agricultural farm in the western part of Germany (North-Rhine Westphalia) had been cultivated with different annual and perennial fruit crops on 18 plots with well-documented individual cropping history. Pome and stone fruits (leading crop), strawberries and currants (minor area) were grown on these plots in different schedules (Fig. 3). For plant protection purposes, the product EUPAREN containing the fungicidal active ingredient dichlofluanid and later tolylfluanid at 50\% (w/w) had been applied between 1993 and 2006. Annual use rates of $1.5 \mathrm{~kg}$ active ingredient/ha on pome fruits, $3 \mathrm{~kg}$ active ingredient/ha on stone fruits, $5 \mathrm{~kg}$ active ingredient/ha on currants and $6 \mathrm{~kg}$ active ingredient/ha on strawberries were applied. The upper soil layer (loam) consists of cambisol from relict high flood alluvium from the Pleistocene and Holocene. An overview of the area of concern including the main information can be seen in Fig. 4.

Catchment and aquifer The orchard is located in the Lower Rhine Valley. The western borderline of the catchment area is the river Rhine and the eastern part is confined by the edge of the Rhine basin consisting of older geological structures from the Tertiary and the Pleistocene at the surface, which constitute a natural border to the aquifer. The groundwater flow is directed across the slope towards the river Rhine, the main receiving water course. The aquifer consists of deposits of fluviatile sand and gravel terraces from the Quaternary with its typical high permeability. The thickness ranges from nearly zero at the eastern valley margin to up to $25 \mathrm{~m}$ at some locations. The aquifer base consists of fine sediment layers composed of sand and clay of marine origin from the Tertiary that are nearly impermeable to water. The aquifer is overlain by a postglacial cohesive loamy top layer from the Holocene. This layer shows a significant variability of its thickness $(0.7 \mathrm{~m}$ to $1.8 \mathrm{~m})$ within a small lateral scale of some 10-m distance.

The lower boundary of that layer is the upper limit of the aquifer. Within the Quaternary sand and gravel layer, the aquifer is unconfined. Only in exceptional cases, when the water level reaches the topsoil layer, does it become a confined aquifer. The long-term variation

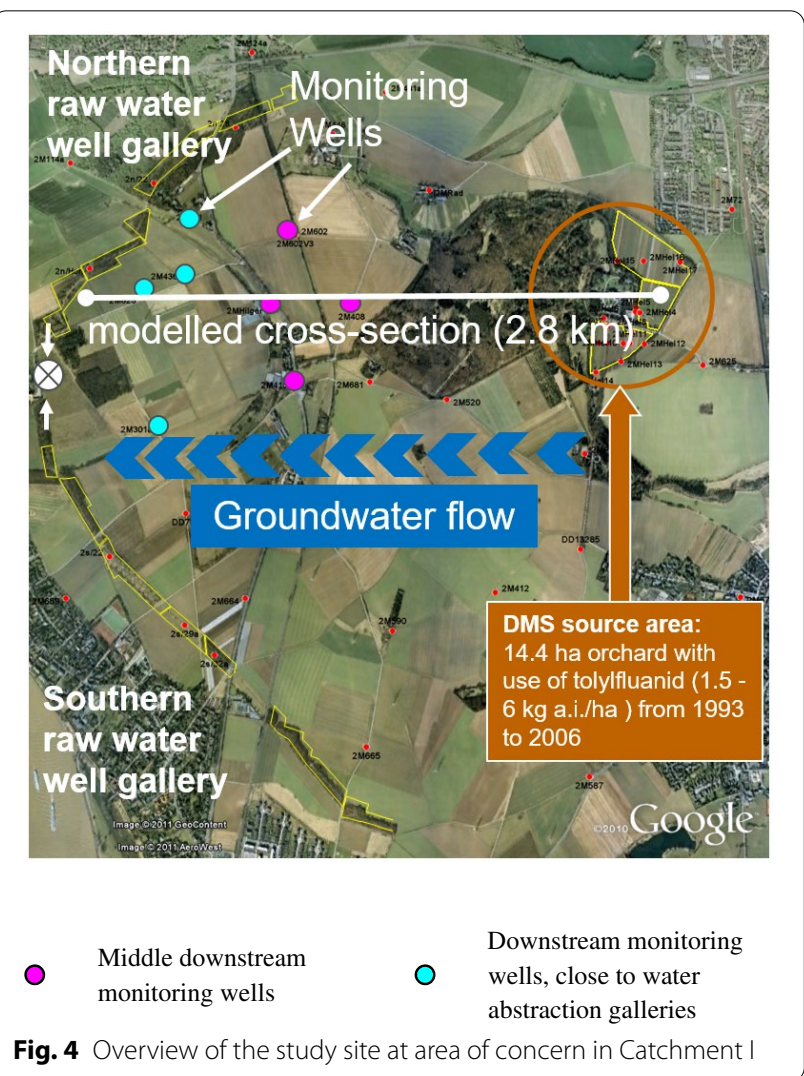

of the groundwater table amounts to ca. $2 \mathrm{~m}(4.5 \mathrm{~m}$ to $6.5 \mathrm{~m}$ below ground surface) [Information based on data from unpublished expert report from GEOBIT Ingenieur-Gesellschaft $\mathrm{mbH}, 2013$ [17] and the concerned waterworks].

\section{Monitoring}

Leachate monitoring Leachate samples were taken from 21 sites distributed across the orchard. In this process, percolate was sampled at the interface between the saturated and unsaturated zone in late spring 2008,2010 , and 2011. Thus, the monitored leachate concentrations could be used for calibration and validation of the breakthrough simulation done with PEARL. The procedure of leachate modeling is described in detail in "Modeling" section.

A filter probe (high-density polyethylene, $36 \mathrm{~mm}$ outer diameter) connected to a hollow drill pipe was used for sampling (Carl Hamm, Essen, Germany), following drilling with a hydraulic core driller. The groundwater table was detected with an electric contact meter. Groundwater was pumped with a foot valve pump through a polyethylene tubing to ground surface. 


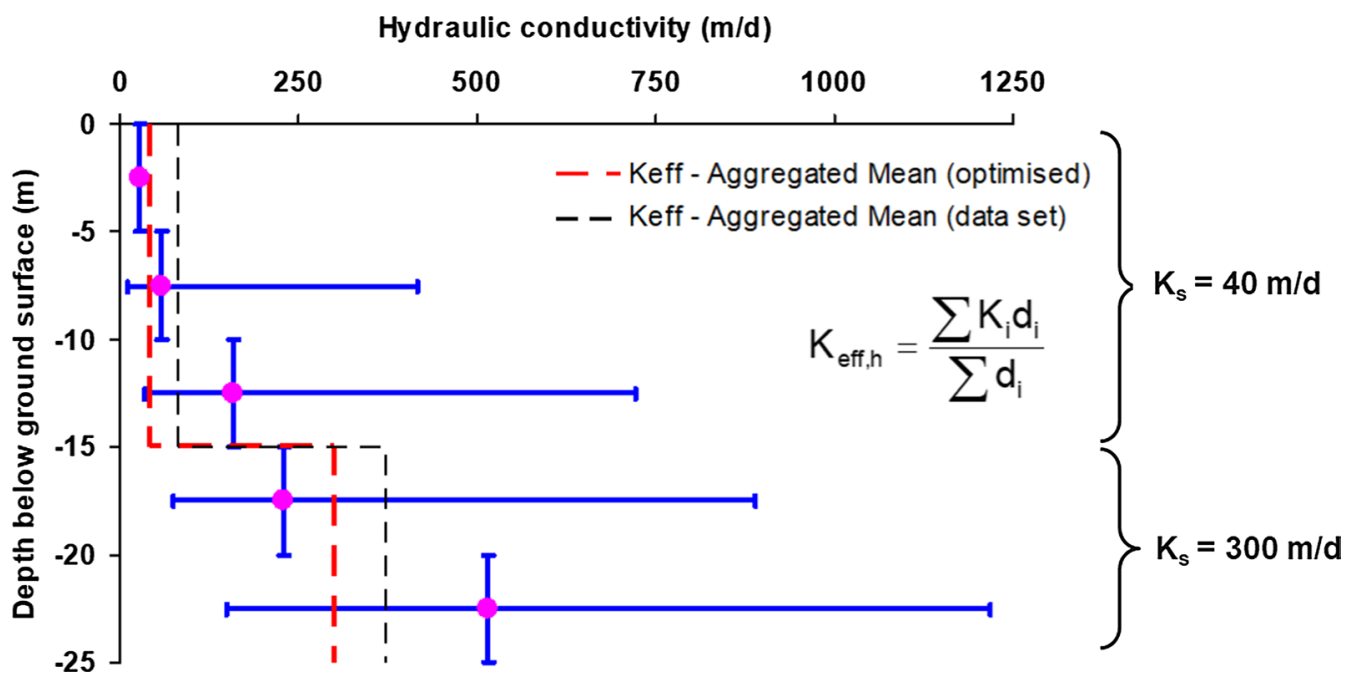

Fig. 5 Hydraulic conductivity measured in different depths of the aquifer (range of measurements marked blue)

Aquifer monitoring The upper third of the aquifer directly under the orchard was sampled heterogeneously at 17 permanent observation wells sporadically at a frequency of several months between February 2005 until May 2016. Unpublished data on aquifer monitoring at this site was provided by a non-disclosed water treatment plant (Anonymous, 2016).

Two groups of four monitoring wells each, downstream of the treated area and at a distance of 1.6 and $2.2 \mathrm{~km}$ from the drinking water well gallery (as shown in Fig. 4), were additionally sampled. For each of these two groups of monitoring wells, nodal simulation outputs were generated. Thus, the related DMS concentrations from monitoring could be used for calibration and validation of the groundwater transport simulation performed with the model HYDRUS 2D [18]. The modeling approach of DMS transport in the aquifer is described in detail in "Aquifer transport modeling" of Catchment I under "Methods".

Hydraulic conductivities in aquifer Depth-resolved horizontal hydraulic conductivities in the aquifer were investigated at ten different observation wells across the catchment area.

In a first step, integral transmissivities (unit: $\mathrm{m}^{2} / \mathrm{s}$ ) across the entire thickness of the aquifer were determined using pumping tests over a duration of $1 \mathrm{~h}$. This was considered to be sufficient based on experience from previous tests. Pumping well discharge rate (unit: $\mathrm{m}^{3} / \mathrm{s}$ ), drawdown and recovery of the water table after test termination were recorded with data acquisition rates between $1 / \mathrm{s}$ and $1 / \mathrm{min}$.

The drawdown phase was evaluated following the approach described by Cooper and Jacob (1946) [19] and the recovery phase following the approach by Theis (1935) [20]. Dividing the transmissivity with the thickness of the aquifer gives the average hydraulic conductivity (unit: $\mathrm{m} / \mathrm{s}$ ). Additional flow meter measurements were conducted while pumping to resolve this average value into its horizon-specific components. A thermal flow meter (Berghof Analytik + Umweltengineering, 2010, Tübingen, Germany) was used, combining high spatial resolution of some $10 \mathrm{~cm}$ with high sensitivity, allowing the detection of very low flow rates down to the millimeter per second range.

In a homogeneous and isotropic aquifer, the vertical water flow rate in an observation well increases linearly from bottom to top. Hence, if the flow meter is moved at constant velocity through the well, the change of the flow rate with depth is constant. Every change of the slope is a consequence of a change in the transmissivity at the corresponding depth. During the flow meter measurement, the pump was positioned in the uppermost part of the filter section.

The resulting hydraulic conductivity values, based on data from an unpublished expert report [21] can be seen in Fig. 5.

Modeling The modeling concept at Catchment I with the given data was separated into two parts. First, the onedimensional leaching model PEARL [12] was used to calculate the loading of DMS to the aquifer. The DMS concentration in leachate at $1 \mathrm{~m}$ depth, was simulated within this process, too. And second, the use of a horizontal 2D model was essential to get a comprehensive understanding of long-term mixing and dilution of DMS in the aquifer. 


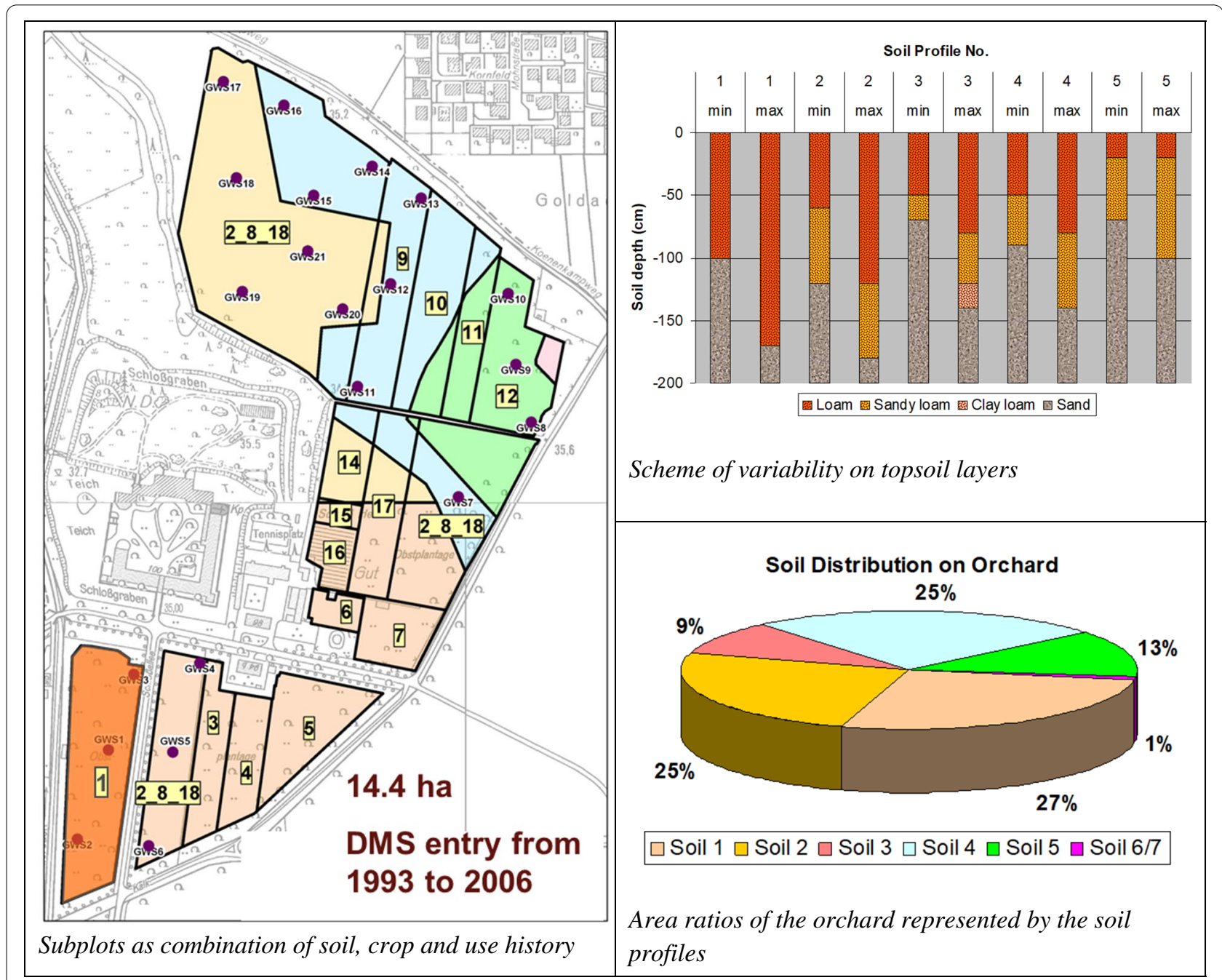

Fig. 6 Conceptual overview of the definition of subplots in Catchment I

The two-dimensional model HYDRUS-(2D/3D) [18] was parameterized to describe the transport of DMS across the aquifer from the site of its entry under the orchard to the drinking water abstraction wells.

Leaching modeling The orchard was discretized into sub-plots with the same soil and crop (use) history. Respective soil hydraulic parameters were derived from the texture class (USDA) using the ROSETTA pedotransfer functions [22, 23] and implemented as scenario parameters into the parameter input file.

The substance parameter set for modeling was defined as described in "Physico-chemical properties" section. Since DMS was applied as "pseudoparent", the application rates were adapted by multiplying the molar mass correction factor (molar mass of DMS divided by molar mass of parent) with the formation fraction of DMS. The interception from individual crops was also considered, according to the recommendations of the FOCUS group [14]. This approach was used in the same way for simulations at other study sites, too.

Daily local weather data in daily resolution until October 2007 were used for the atmospheric boundary condition. Minimum and maximum air temperatures, precipitation levels, air humidity and wind speed were taken from the nearby weather station Düsseldorf (German Weather Service, $\left.51^{\circ} 17^{\prime} \mathrm{N} 06^{\circ} 46^{\prime} \mathrm{E}\right)$. And solar radiation measurements were taken from a weather station in Monheim/Rhein (Bayer Crop Science, $51^{\circ} 06^{\prime} \mathrm{N}$ $06^{\circ} 54^{\prime} \mathrm{E}$ ). For future projections the weather dataset was prolonged in two variants; one representing a relatively wet decade in this region (1997-2007) and a second representing a relatively dry decade (1988-1998). 
For each subplot, the monthly leachate mass of DMS and water volumes at groundwater table depth were calculated applying a free drainage boundary condition at the bottom of the soil profile.

As a significant variability in the thickness of the loamy topsoil layers was observed over a small spatial range, half of the subplot was calculated using the maximum depth and the other half with the minimum depth of the loamy layer. By combining these different soil types with two depths each with the connected cropping and pesticide use history, about 50 subplots were defined (see Figs. 3, 6).

The results of all calculations were finally combined to calculate an area weighted average concentration of DMS for larger parts and for the entire orchard. Using the same procedure, a leaching curve at $1 \mathrm{~m}$ depth was calculated.

Additionally, the FOCUS standard scenario "Hamburg" with predefined modeling parameters was simulated [14]. This was done in order to have an optional comparison of individual modeling with predicted environmental concentrations in groundwater (PECgw) as used for risk assessments in a European regulatory context. As usual in European risk assessments, a continuous yearly application over 26 years (incl. 6 years warm-up period) was performed. To make the results comparable with the individual scenario, application rates of "usual practice" were calculated. In a regulatory context, calculations with maximum labeled application rates would be required. Calculations of the FOCUS standard scenario "Hamburg" were performed also for both other study sites in the same manner.
Aquifer transport modeling The DMS transport simulation in the aquifer was aimed to determine the fate of DMS on the way from below the orchard to the raw water abstraction wells. For this purpose, the 1D leaching results generated using PEARL served as upper boundary conditions (DMS loading) in the source area to the HYDRUS 2D aquifer model. In the course of the simulated transect, DMS concentrations were read out at positions that correspond to monitoring sites in the downstream area in front of the raw water abstraction gallery (see Fig. 7). The horizontal hydraulic conductivity in the aquifer is highly variable within the catchment. Since it generally increases with depth, the use of mean values for the upper and lower part of the aquifer was preferred. For modeling purpose hydraulic anisotropy of the aquifer was assumed. Vertical hydraulic conductivity was one tenth of horizontal hydraulic conductivity. The tensor of hydraulic anisotropy $\left[\mathrm{K}^{\mathrm{A}}\right]$ was determined according to Eq. 1:

$$
K^{\mathrm{A}}=\left[\begin{array}{cc}
K^{\mathrm{A}} & 0 \\
1 & \\
0 & K_{2}^{\mathrm{A}}
\end{array}\right]=\left[\begin{array}{cc}
1 & 0 \\
0 & 0.1
\end{array}\right]
$$

This calibration led to a slight reduction of the hydraulic conductivity in the model (red line) in relation to the weighted geometric mean of measured values (black line). Ksat was calibrated to $40 \mathrm{~m} / \mathrm{d}$ in the upper $10 \mathrm{~m}$ of the aquifer and $300 \mathrm{~m} / \mathrm{d}$ in the lower $5 \mathrm{~m}$ of the aquifer (see also Fig. 5). The integral hydraulic conductivity over the entire thickness amounted to $0.0015 \mathrm{~m} / \mathrm{s}$.

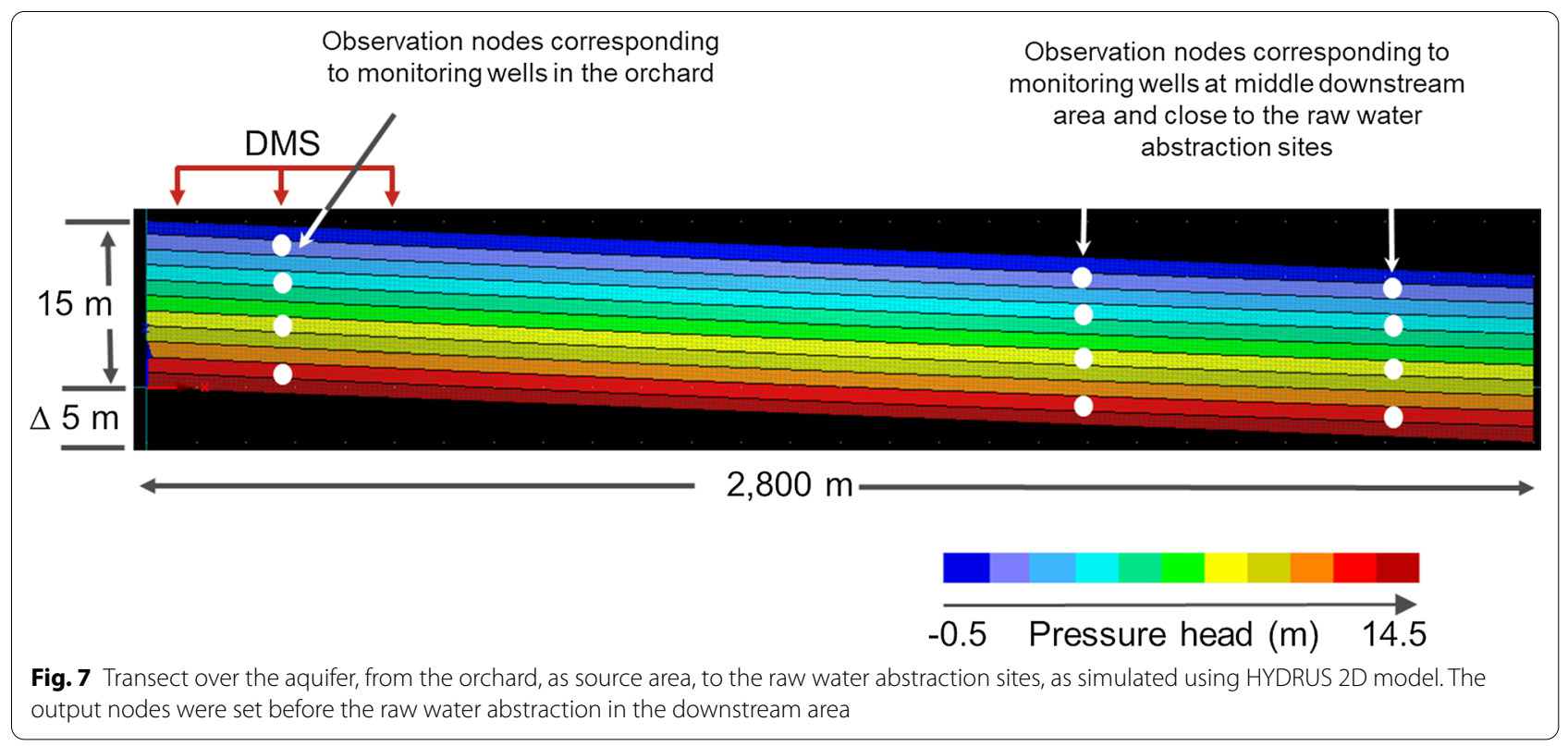


For the parameterization of the model, an aquifer of mainly fluviatile sand and gravel, with small amounts of finer-grained alluvium, was supposed. Measured data or plausible assumptions for general geometry of the aquifer, porosity (0.2), hydraulic anisotropy, longitudinal and vertical dispersivity (10/0.1 m) were chosen [24]. A constant pressure head boundary condition and a slope of $5 / 2800$ m generated Darcy-type flow in HYDRUS.

DMS concentrations at the raw water abstraction itself were not simulated, since inlet from other directions could not be taken into account. Even minor changing flow rates over time would have much more direct impact on the flow in the aquifer and affect concentrations.

Catchment I-compact summary The main facts regarding Catchment I are presented in Table 2. A concise overview about the environmental conditions and basics of the site-specific modeling approach is provided there.

\section{Case study of Catchment II-Lower Rhine Bay}

The site Catchment II is also an agricultural farm close to the river Rhine in the western part of Germany (NorthRhine Westphalia). Since this farm is used as an agronomic trial station, the use history is well-documented and local weather and soil data is available. This case study is based on a treated area as source of DMS with a size of 12 hectares. This study site was a long-standing apple orchard. For plant protection purposes, the fungicidal active ingredient dichlofluanid was applied between 1996 and 2000 with annual use rates of $2.5 \mathrm{~kg} /$ ha to $6.25 \mathrm{~kg} / \mathrm{ha}$. In 2006, a small amount of tolylfluanid of $0.17 \mathrm{~kg} / \mathrm{ha}$ was applied. The conditions of the subsurface at Catchment II are quite similar to the situation in Catchment I. A loamy upper soil is developed as cambisol from relict high flood alluvium from Pleistocene and Holocene. An overview of the area of concern including the considered monitoring wells, abstraction points and hydraulic conductivities can be seen in Fig. 8. Aquifer modeling is explained in detail in "Aquifer modeling" of Catchment II under "Methods" section.

Catchment and aquifer This second study site is also located in the Lower Rhine Valley, approx. $40 \mathrm{~km}$ south of Catchment I. This groundwater catchment area is bordered by the Rhine River in the west and the edge of the Rhine basin in the east, too. The depth of the upper level of groundwater under the soil surface of the orchard ranges from 7.5 to $12.5 \mathrm{~m}$. In the catchment area of concern, the Quaternary base as lower boundary of the aquifer, is located at a depth of 23 to $33 \mathrm{~m}$. The resulting thickness

Table 2 Compact summary of Catchment I

\begin{tabular}{|c|c|}
\hline \multicolumn{2}{|l|}{ Crops and use history } \\
\hline Treated crops & Stone and pome fruits, strawberries currants \\
\hline Application & 1993-2006; application in late spring and summer, BBCH growth stages > 60 \\
\hline \multicolumn{2}{|l|}{ Observation } \\
\hline Leachate sampling & Collected at 21 sites, distributed across the orchard in 2008, 2010, 2011 \\
\hline Position of monitoring wells & Below orchard Middle downstream Close to the raw water abstraction Raw water abstraction gallery \\
\hline $\begin{array}{l}\text { Distance of treated area to downstream } \\
\text { monitoring wells [m] }\end{array}$ & $-\quad \sim 1600 \quad \sim 2200 \quad \sim 2800$ \\
\hline \multicolumn{2}{|l|}{ Geology/lithology } \\
\hline Leaching profile & Holocene loam (Cambisol) from relict high flood alluvium covering Pleistocene sands \\
\hline Aquifer & Quaternary fluviatile sand and gravel terraces \\
\hline Basement & Tertiary fine sediment layers composed of sand and clay of marine origin \\
\hline Location & Western Germany, Rhine-Ruhr region \\
\hline Topography & Rhine plain (east of the river) with slope $<1^{\circ}$, agricultural land use \\
\hline \multicolumn{2}{|l|}{ Aquifer properties } \\
\hline $\begin{array}{l}\text { Groundwater level below treated orchard } \\
\text { [m] }\end{array}$ & $4.5-6.5$ \\
\hline Thickness $[\mathrm{m}]$ & $1-25$ \\
\hline Slope of aquifer $[\mathrm{m}] /[\mathrm{m}]$ & $5 / 2800$ \\
\hline Hydraulic conductivity $[\mathrm{m} / \mathrm{d}]$ & $\begin{array}{l}40 \text { (upper } 10 \mathrm{~m} \text { ); } \\
300 \text { (lower } 5 \mathrm{~m} \text { ) }\end{array}$ \\
\hline Dispersivity (longitudinal/vertical) [m]; [m] & $10 ; 0.1$ \\
\hline \multicolumn{2}{|l|}{ Used models } \\
\hline Leaching modeling & PEARL \\
\hline Aquifer transport modeling & HYDRUS-2D \\
\hline
\end{tabular}




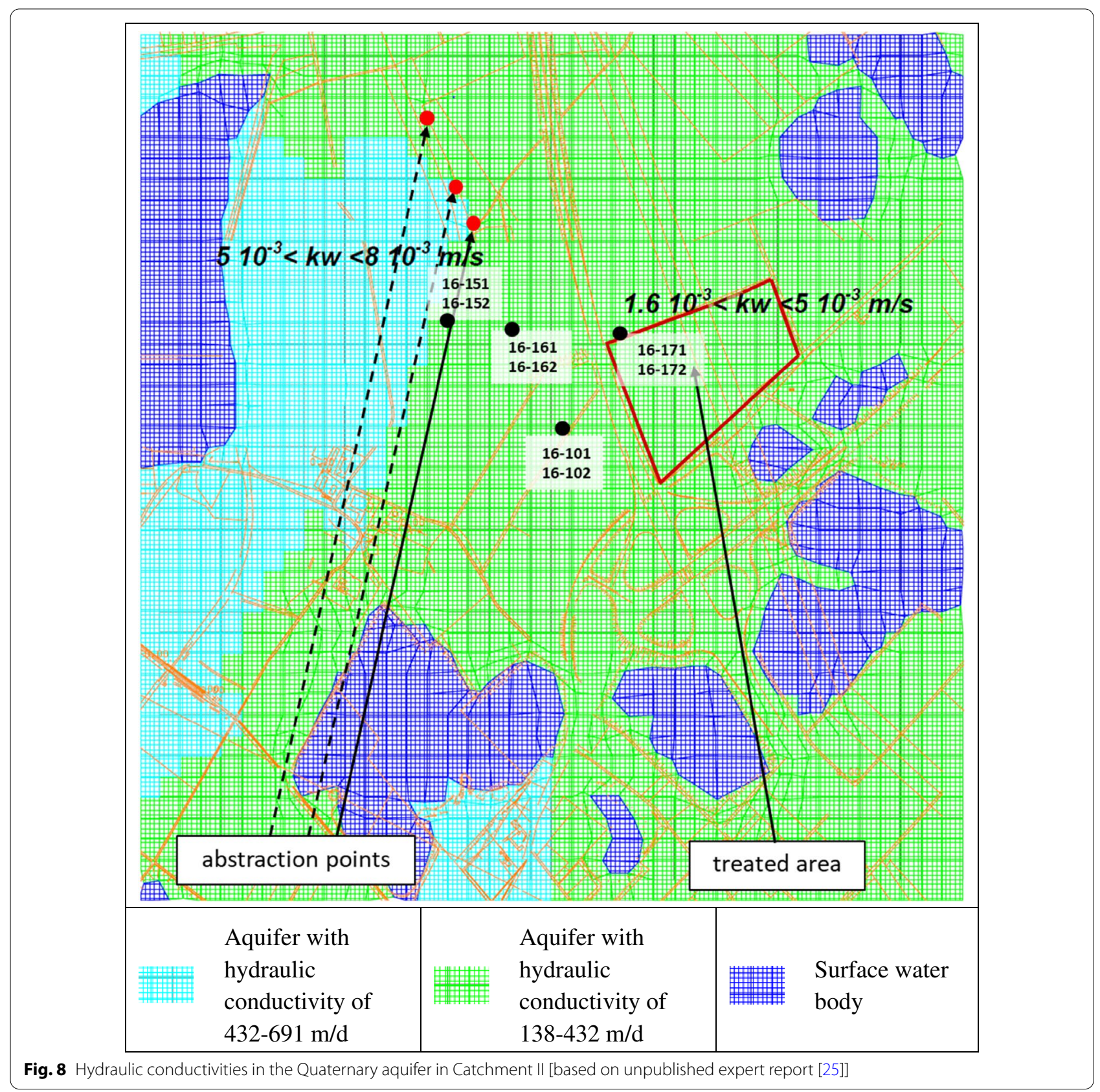

of the waterbody in the sand and gravel terraces is in the range of 16 to $22 \mathrm{~m}$ [based on data from unpublished expert report [25] and the concerned water treatment plant].

\section{Monitoring}

Leachate monitoring Directly on the orchard, no samples of pore water in the matrix or percolate at the interface to the aquifer were taken.

Aquifer monitoring Several permanent monitoring wells are positioned on the upstream area of the raw water abstraction wells. Several of these monitoring wells are located downstream of the treated area on the flow pathway towards the abstraction wells. The monitoring points are divided into two units: one has its filter screen in the upper part of the aquifer ( upper quarter), while on the other one, the aquifer part deeper than the upper monitoring well unit can be sampled [unpublished monitoring well data sheets; anonymous; 2020]. The monitoring wells are grouped by their location between the treated area and the abstraction wells. In Fig. 9, an overview of the local distribution of monitoring wells is given. 
Most representative for the situation below the treated area, is a groundwater monitoring well pair, immediately next to it in downstream position (16-171/16-172). A bit more remote, but still close to the orchard $(\sim 200 \mathrm{~m})$ the pair of monitoring wells $16-101 / 16-102$ is positioned. In the middle of the downstream area $(\sim 400 \mathrm{~m})$ two pairs of monitoring wells are relevant and nearly in the same distance (16-151/16-152; 16-161/16-162). Concentrations at the crucially affected raw water abstraction well (600-700 m) were also taken into account to evaluate the attenuation (17-915). Since the concentration is probably influenced by other local DMS sources and measured data are available, a local background concentration was evaluated in addition. Groundwater samples for DMS residues analysis were taken each year in May from 2006 onwards. Unpublished data on aquifer monitoring at this site was provided by a non-disclosed water treatment plant (2020) and Bayer AG (2020) as well.

Hydraulic conductivity in aquifer According to an unpublished expert report [25], the transmissivity across the entire thickness of the Quaternary aquifer was quantified in a range of $0.016-0.15 \mathrm{~m}^{2} / \mathrm{s}$. The hydraulic conductivity of the aquifer was determined by model calibration in a range of $138-691 \mathrm{~m} / \mathrm{d}$ with a mean of $285 \mathrm{~m} / \mathrm{d}$ (Fig. 8). The dredging lakes were simulated in the model with a permeability value of $1 \mathrm{~m} / \mathrm{s}$ and a storage coefficient of 1 .

Modeling The modeling concept at this site with the given data was separated into two parts. One part was to simulate DMS leaching at $1 \mathrm{~m}$ depth and at breakthrough using PEARL, since no measured data was available. As a second part groundwater flow paths were simulated to identify relevant monitoring wells and the velocity of groundwater flow, using an in-house developed streaming model [25].

Leaching modeling At this site, the one-dimensional leaching model PEARL [12] was used to calculate the breakthrough of the DMS concentration curve under the treated orchard. The model was parameterized with a well- documented use history, local weather data as well as local soil parameters. Local weather data from the agronomic trial site, in daily resolution until February 2006 (minimum and maximum air temperatures, precipitation levels, air humidity, wind speed, solar radiation) were used to establish the atmospheric boundary condition. Local soil parameters were combined from two profiles, based on two unpublished reports on determination of soil characteristics [26, 27]. For the topsoil layer $(30 \mathrm{~cm}$, loam) parameters could be determined from a soil sample directly from the orchard. Parameters for deeper subsoil layers were not available immediately from the orchard. Therefore, the deeper soil profile for modeling down to groundwater level, was prolonged by a supplementary profile, which was sampled at $\sim 600 \mathrm{~m}$ from the orchard. Hydraulic parameters (v. Genuchten and Ksat parameters) were evaluated by ROSETTA [22, 23] for the use in PEARL. For a warm-up simulation before 1996, as well as for long-term simulations after 2006, weather data from the meteorological database MARS [28] were used. For the simulated soil profile, it was assumed appropriate that leaching down to groundwater level is possible without any waterlogging. As the lower boundary condition at the bottom of the soil profile, a free drainage option was chosen.

Given the short use history of only 5 years, a single unusual constellation of the annual water balance, has a high influence on averaged concentrations. Based on the used weather dataset, unusual dry weather conditions with a considerable low groundwater recharge in the three consecutive years 1996 to 1998 and an enormously high recharge in the following year 1999 were identified. In a simulation this led to the effect, that DMS mass from several years coeluted in one single year, what resulted in a high increase compared to the upper soil layer. Thus, a very anomalous inversion of the DMS concentrations in the lower layers of the unsaturated zone would occur. To reduce this effect, the simulated application period was prolonged by the same application cycle as the documented use history (1996-2000). The resulting basis for the average concentrations in $1 \mathrm{~m}$ depth, as well as for the breakthrough, was an application period from 1991 to 2000.

Output was generated for two depths in the soil column. First, at $1 \mathrm{~m}$ depth, to have a value comparable with results of a regulatory risk assessment. Second, the mean groundwater level below the orchard at a depth of $9.5 \mathrm{~m}$ was calculated to simulate a breakthrough curve.

Aquifer modeling Modeling of DMS transport in this aquifer was not explicitly conducted. However, the streaming model "Bayerwerk Leverkusen" was applied to the catchment in an unpublished expert report [25]. In this in-house (from Bayer AG, Leverkusen, Germany) developed groundwater flow model, the direction of the flow and its velocity were calculated according to the Darcy law.

Therefore, it takes approximately 1-2 years for the groundwater in the aquifer under the treated field to reach the abstraction wells (see Fig. 9).

The calculation of these flow paths and flow times is based on the calculated groundwater level heights and the gradients determined from them (direction and slope of the groundwater level) as well as on the porosity affecting the flow. The flow velocity $v$ is directly proportional to the specific flow rate $q$, according to Darcy, and indirectly proportional to the flow-effective porosity $n: v=q / n$, where $q$ is determined by the product of permeability $k$ 


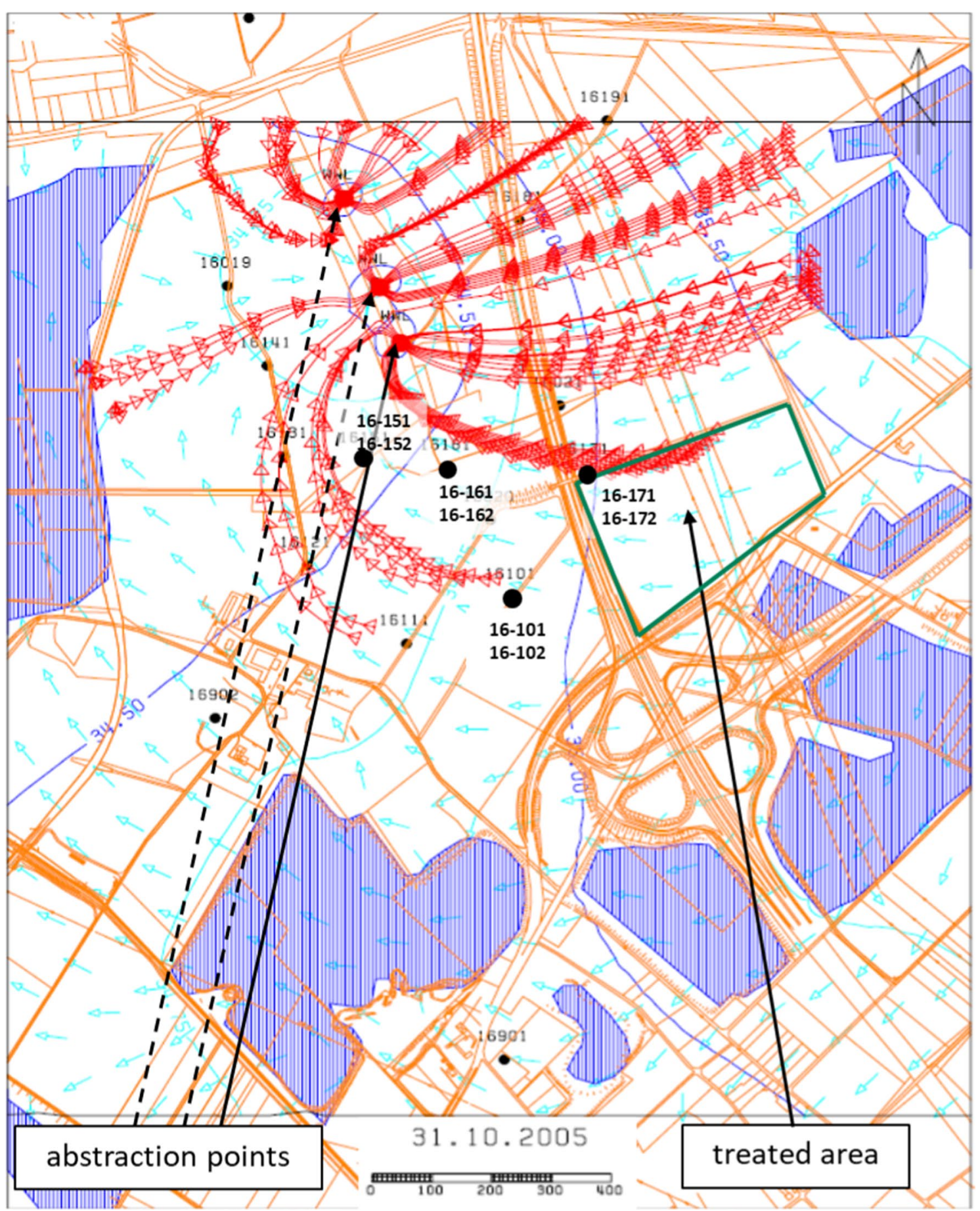

Fig. 9 Overview on the area of concern at treated site in Catchment II with calculated groundwater flow (end of 2005); flow time between two following arrows of direction amounts 30 days; solid line marks the mainly affected abstraction well 17-915 (based on unpublished expert report [25]) 
and the slope of the groundwater table i: $q=k \times i$. From the flow velocity and the flow direction, the flow paths can be calculated one by one for each time step, starting from a starting point, and joined together to form flow paths. The calculation of the flow paths and flow times is based on a flow-effective porosity of $15 \%$. Since DMS behaves like a tracer in the saturated zone, it was assumed that the contamination plume moves with the simulated flow direction and within a similar time space.

Catchment II-compact summary The main facts regarding Catchment II are presented in Table 3. A concise overview about the environmental conditions and basics of the site-specific modeling approach is provided there.

\section{Case study of Catchment III-Upper Swabia}

The 2.5-ha treated area is located in Upper Swabia in Southern Germany (Baden-Württemberg). An overview of the study site can be seen in Fig. 10. The field was used perennially from 1980 to 1990 for cultivation of strawberries. Over this time, the fungicidal active substance tolylfluanid was applied with annual use rates of $12 \mathrm{~kg} /$ ha on the strawberry field. According to the good agricultural practice and the documentation of the farmer, the application dates of the fourfold application (7 days interval) in strawberries were annually placed in May. The ground in the area of consideration is very diverse and multi-layered.

Catchment and aquifer This third case study site is located about $40 \mathrm{~km}$ south of Ulm, close to the river Riß. The naturally receiving waterbody (without the influence of abstraction) for the outrunning groundwater in the area of concern is a minor stream. It flows past to the east at a distance of approx. $100 \mathrm{~m}$. This stream runs in a loop around an elevation and thus, comes from the western groundwater inflow area of the catchment area. Earlier discharge measurements of the stream showed relatively high water losses, which indicate a high infiltration at the eastern bank of the stream into the aquifer. This surface water, seeping into the groundwater from the river bank side, influences and significantly increases groundwater recharge in the inflow area of the catchment area. Especially the inflow pathway to the drinking water collection at the eastern side of the elevation is affected. Naturally,

Table 3 Compact summary of Catchment II

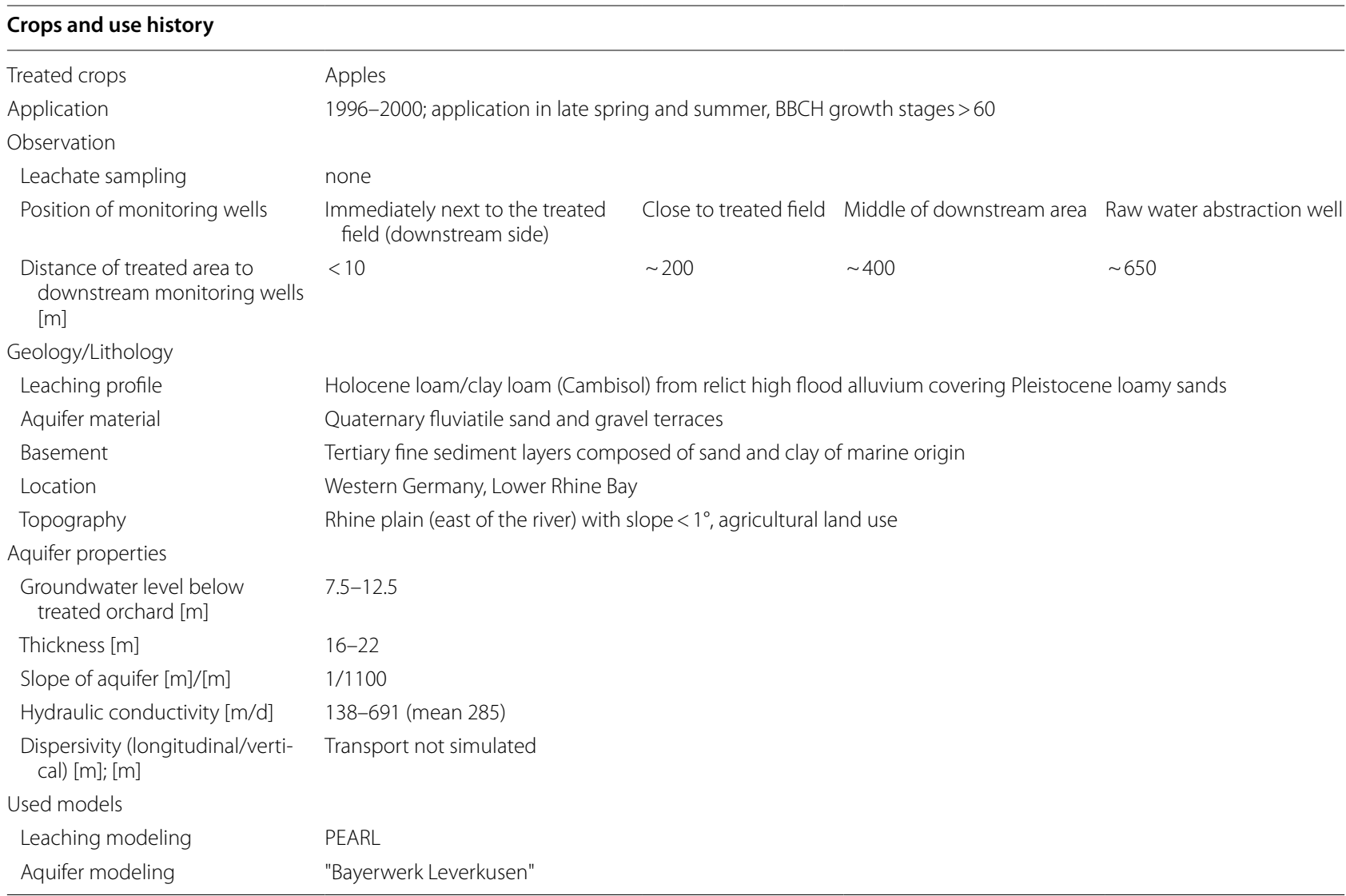




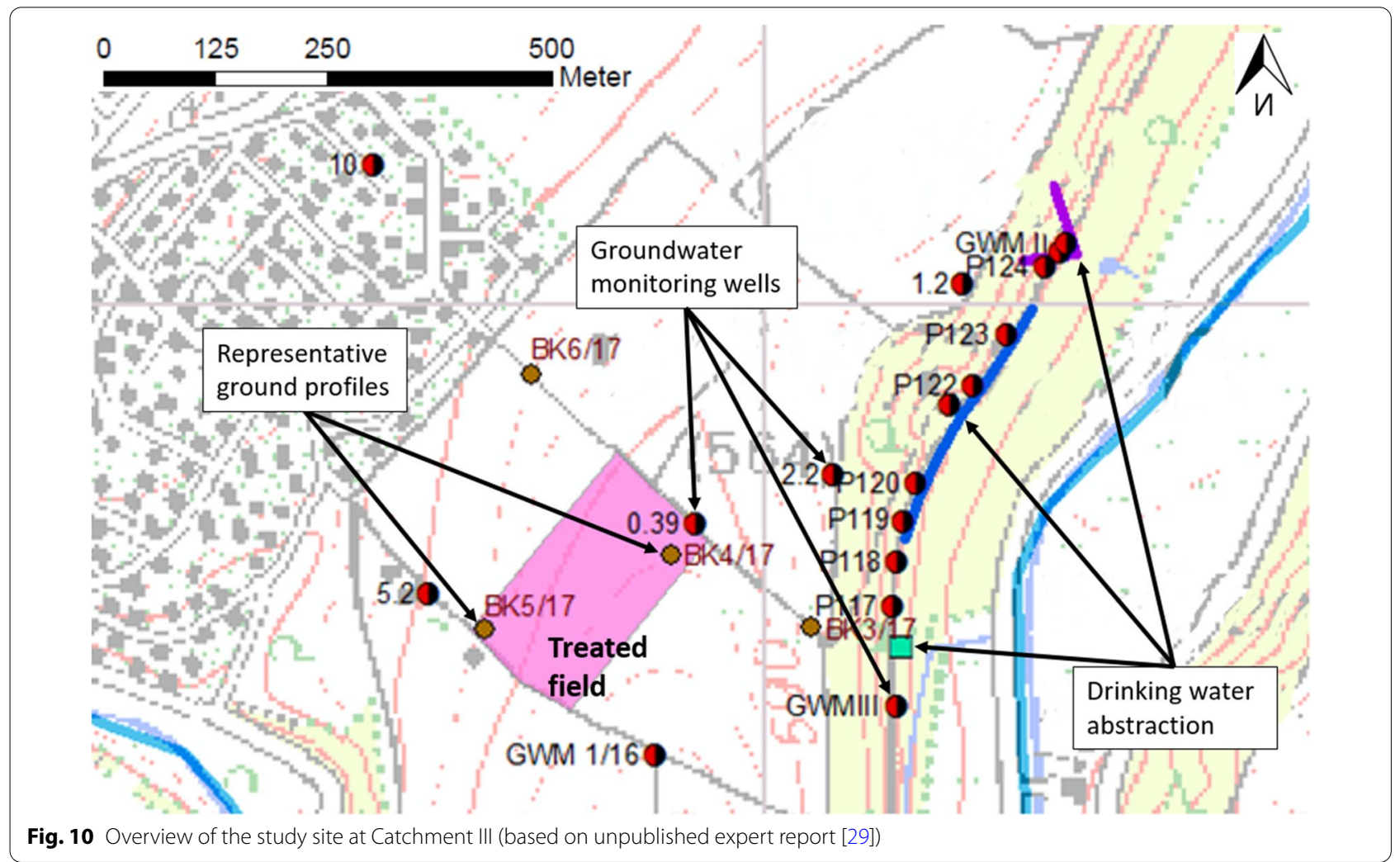

groundwater flow from the considered part of the catchment is leaving at the east side, back to the river via natural springs. From this throughflow below the area of concern a major part is collected as raw water via drainage systems.

The upper soil is characterized as luvisol of loess loam. Also, the further subsurface structure is characterized by Quaternary deposits, where glacial sediments reach down to depths of 10 to $20 \mathrm{~m}$. The sediments are mainly silt/marl and gravel, which are not very permeable. They are assigned to the Riß ground moraine. Below this are advancing gravel from the Riß Ice Age, which are formed by highly water-permeable sandy gravel. The subsurface is often consolidated to conglomerate (Nagelfluh) and merge into the high terrace gravel of the region. The water outlet from this "Dietmanns-formation", an unconformity-bounded unit, is used by the spring collectors of the catchment area. The thickness of the aquifer is approx. $10 \mathrm{~m}$. Below the aquifer, a tertiary basement of the Upper Freshwater Molasse makes up the damming layer for the groundwater. Here, clayey silt dominates the sedimentation sequence. Some silt-dominated horizons and Nagelfluh/conglomerate act as damming layers in different depths of the profile. For this reason, stratified (perched) water occurs at different depths [29-31].

\section{Monitoring}

\section{Leachate monitoring}

One borehole drilling was performed on the strawberry field to get the subsurface profile as well as the recent DMS concentration in the pore water. Therefore, at bore BK4/17, composite samples of the percolate were taken and analyzed from the drilling material in 5-m segments, each up to $38 \mathrm{~m}$ depth. Immediately next to the treated field a further bore (BK5/17) was drilled. From this borehole also the subsurface profile was determined, and the percolate was analyzed for DMS.

Aquifer monitoring As on the other sites, in the area of Catchment III, a number of permanent monitoring wells are positioned downstream from the treated field before the raw water collection system (see Fig. 10). Three monitoring wells are directly on the pathway of the groundwater flow from the field to the raw water collection. The first one (GWM 39) is located directly next to the field. It provides a good representation of the DMS concentration in the contamination plume next to the area of entry.

Two further monitoring wells (GWM 2.2 and GWM III) are located $\sim 150$ to $300 \mathrm{~m}$ from the treated field and only 20 to $50 \mathrm{~m}$ upstream from the raw water collection gallery. Both of these monitoring wells mark the fringe area of the DMS dispersion plume. 
The drinking water collection at this site works as a permanent free draining system. It catches nearly all the outflow from the smaller catchment area part, which is loaded with DMS. Another DMS entry source, which could reach the raw water collection system is not assumed. Because of this very local situation, even the DMS concentration in raw water can be seen as a result of attenuation from this treated field, which is why it was taken into account.

Thus, the related DMS concentrations from monitoring could be used for calibration and validation of the groundwater transport simulation performed with the model FEFLOW [32]. The modeling approach of DMS transport in the aquifer is described in detail in "Aquifer transport modeling" of Catchment III under "Methods".

Hydraulic conductivities in aquifer During the preparation of the groundwater model in 2009, preliminary investigations determined a hydraulic conductivity of $43-86 \mathrm{~m} / \mathrm{d}\left(5 \times 10^{-4}\right.$ to $\left.1 \times 10^{-3} \mathrm{~m} / \mathrm{s}\right)$ for the relevant groundwater-conducting layers Fig. 11. [29]. The hydraulic parameters were determined in the context of an expert report [30] by evaluation of pumping test results from the catchment, according to the approach from Cooper and Jacob (1946) [19] and Theis (1935) [20], as described in "Hydraulic conductivities in aquifer" of Catchment III under "Methods" section. Due to this relatively high hydraulic conductivity, the flow time from the stream in the west to the withdrawal at the east border of the catchment is about 5 years [29].

Modeling Since the ground in the area of consideration is very diverse and multi-layered, a coupled approach of three models was chosen for modeling of the DMS percolation, leaching and the transport in the aquifer (see Fig. 12). The common model PEARL was used to get a simulation that is comparable to those of the other two study sites with the same predefined crop scenarios and boundary conditions at the surface. Due to technical limitations in PEARL, the model cannot calculate more than 10 layers. Since the considered profile has 15 layers, the leaching simulation had to be split.

Modeling the $47.5 \mathrm{~m}$ deep profile BK4/27 was performed by the separation into its 15 layers: three in PEARL (down to $1 \mathrm{~m}$ ) and 12 in HYDRUS-1D (down to the groundwater table). FEFLOW was used to calculate the dispersion plume and the dilution of DMS in the saturated groundwater layer. For this, the calculated hydraulic head of groundwater in the area of concern and the DMS entry via leaching from the vertical 1D simulation were combined. The coupling of the modeled output as upper boundary condition to the next modeling stage was carried out in daily steps.

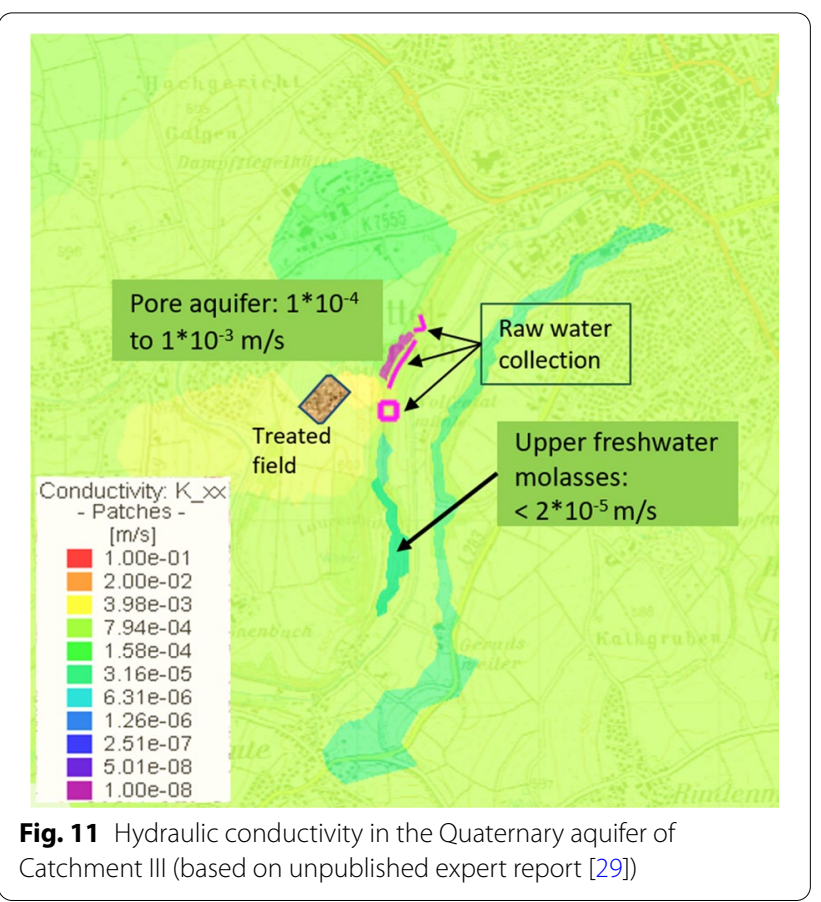

\section{Leaching modeling}

Considered subsurface profiles: Leaching of DMS below the treated field at the site Catchment III has been simulated using two profiles representing the ground below the field. The first bore, BK4/17, was drilled on the northeast corner of the treated field. DMS could be detected in the samples from this profile. However, the drilling was stopped approximately $10 \mathrm{~m}$ above the groundwater level, because of problems with the drilling tool. For modeling purposes, this profile was extended down to the groundwater level by applying the properties of the corresponding $10 \mathrm{~m}$ sequence above groundwater from the nearby profile from bore BK5/17 (see Fig. 13).

The bore BK5/17 was drilled next to the south-west corner of the field (Fig. 10). The surface of the former strawberry field is sloped, so that the distance between the surface and the aquifer differs by almost $8 \mathrm{~m}$ over the distance $(\sim 300 \mathrm{~m})$ from BK4/17 to BK5/17. The conducted analysis showed no detectable DMS residues in the pore water of the soil core material of BK5/17. Nevertheless, due to their spatial position in relation to the treated field, both profiles were considered representative of the subsurface in this part of the field. Though the deeper underground changed considerably in the course of the transect under the field and was showing two largely different profiles. However, the leaching modeling based on these two separate profiles of the relevant 


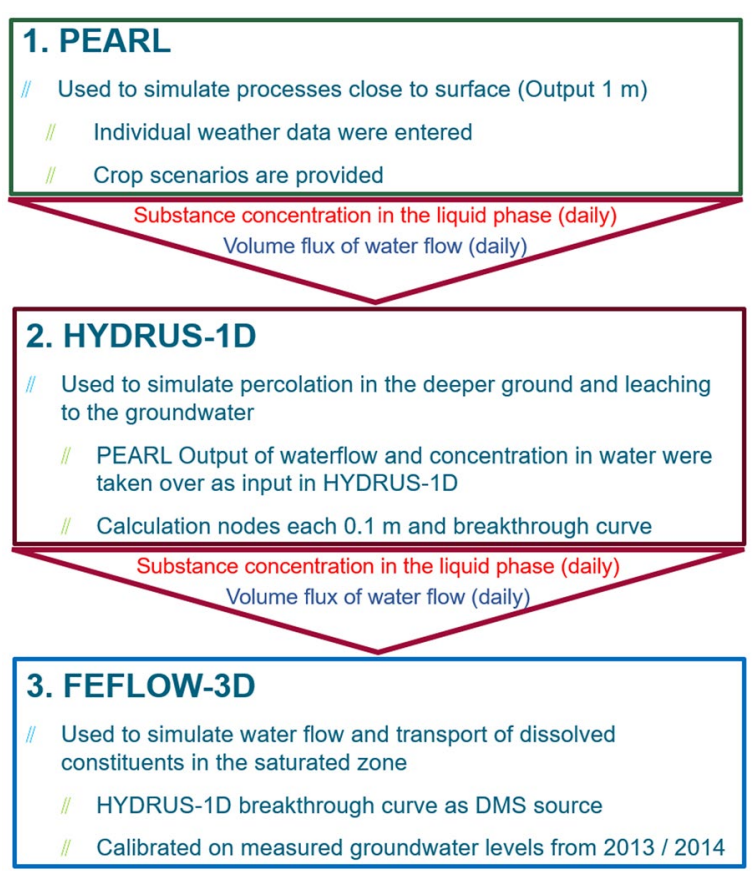

Fig. 12 Conceptual overview of the coupling of models for simulation of DMS leaching and transport in the aquifer

subsurface domain was deemed to be sufficiently accurate, since the mainly important factors coincide. One is, that the upper soil, where degradation happens, is a luvisol of loess loam over the whole area of concern. Another point is, the profiles are heterogenous over their course, but consist of the same source material, which in its development after deposition went through the same geological development. And the other, for modeling important factors, like cropping, pesticide application and meteorological conditions are completely the same on the whole area of concern.

The measured DMS concentrations in the pore water of bore BK4/17 show the distribution of DMS at this time point (Nov. 2017) in the profile. According to this measured distribution of DMS concentrations across the depth of the profile BK4/17, the monitored DMS concentrations in groundwater could not be explained. Chemical analysis of DMS in this profile did not indicate any leaching of DMS to the aquifer, yet. The maximum concentration was still found above the midpoint of the profile even 27 years after the last application (see Figs. 24 and 25). Additional undocumented non-professional uses (e.g., home and gardening) could be a further source of DMS loading to the groundwater. However, this is not indicated by monitoring data from wells in the catchment, upstream of the considered strawberry field. Therefore, only the measurements of DMS in the pore water from the BK4/17 drilling core material were used for calibration and validation of the leaching simulation. This inverse calibration of the soil parameterization was performed stepwise per subsurface layers with PEARL and HYDRUS. A challenge, that had to be addressed in the simulation of percolation in the vadose zone are the highly localized damming layers (especially silt-dominated horizons and Nagelfluh/conglomerate) at different depths.

Leaching curve fitting: For the fitting of the DMS concentrations at a relatively shallow depth in profile BK 4/17 (peak at 15 to $20 \mathrm{~m}$ ), nearly all relevant model parameters were adjusted. Hydrological parameters were derived from Rosetta pedotransfer functions and calibrated. Assumed residual and saturated water contents of the individual horizons were adapted. Standard values of saturated hydraulic conductivity from HYDRUS were reduced in parts of the profile with values representing smaller particle sizes and were increased in coarsely pored horizons as in stratified water horizons $\left(4.1 \times 10^{-8}\right.$ to $4.2 \times 10^{-6} \mathrm{~m} / \mathrm{s}$ ). The dispersion length over the profile gradually increased from $0.01 \mathrm{~m}$ in silty layers to $0.7 \mathrm{~m}$ in sandy gravel, with the exception of the Nagelfluh/conglomerate layer at $34-38 \mathrm{~m}$ depth, where a dispersion length of $0.02 \mathrm{~m}$ was assumed.

To explain the situation, where the main amount of (non-sorbing) DMS was still found, in the middle of the profile, a „Dual-porosity-model” was used to characterize the shape of the profile accurately [18]. Therefore, parameters of various pore spaces with mobile and immobile flow were assumed [33]. Especially in case of a Nagelfluh layer this was of major relevance. To reflect the lower permeability of such conglomerate, this layer was parameterized like pure clay. With respect to permeable fractures in such a layer, which allow groundwater recharge, the porosity was set to $95 \%$ immobile and $5 \%$ as mobile pore volume.

As known for other pesticides, degradation in relevant amounts can sometimes take place in soil still below a depth of $1 \mathrm{~m}$ [34]. For further inverse model calibration, also the parameter of aerobic microbial degradation $\left(\mathrm{DT}_{50}\right)$ was adapted. It was assumed for modeling that the aerobic degradation can be extended below the FOCUS standard of $1 \mathrm{~m}$ depth and takes place in the whole first silty horizon down to $2 \mathrm{~m}$ depth. However, in the sand/ gravel horizon below, hardly any organic material and microbial activity was expected.

Local weather data in daily resolution from 1975 to 2015 (solar radiation, minimum and maximum air temperatures, precipitation levels, wind speed, evapotranspiration) from the MARS database [28] were used for the atmospheric boundary conditions. For future 


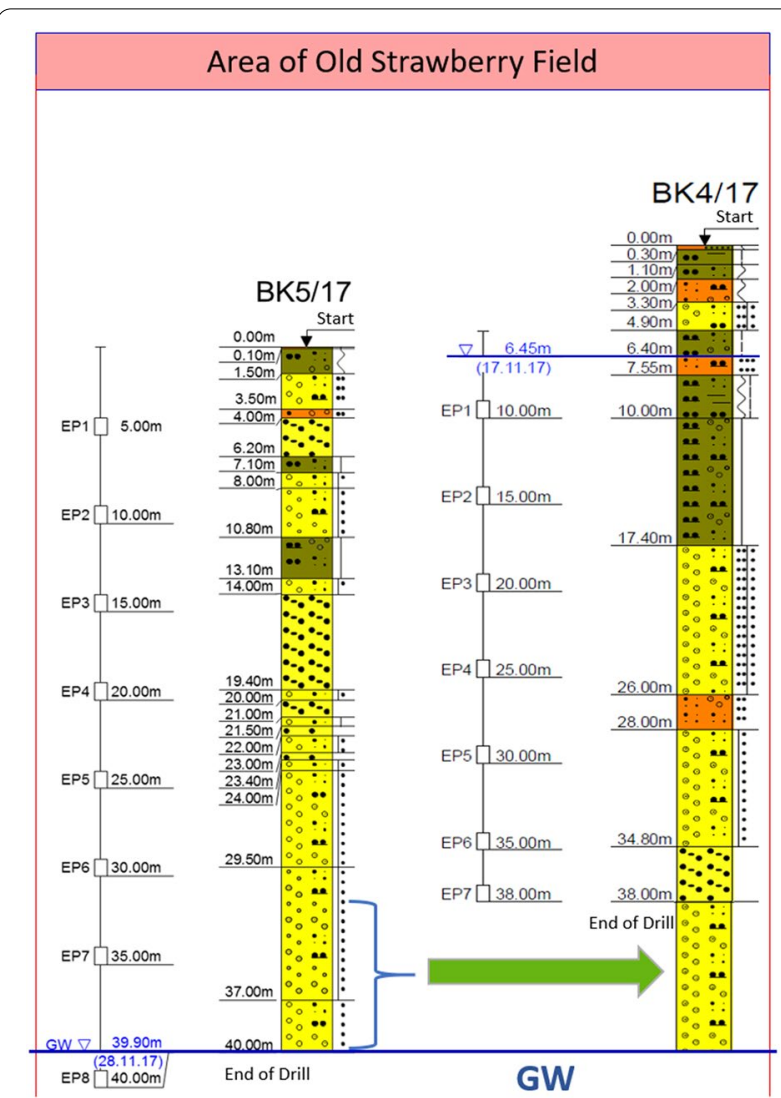

Fig. 13 Profiles representing ground below old strawberry field in Catchment III down to groundwater level

projections, the weather dataset was prolonged by the last 20 years available.

To get stable water conditions in soil, a warm-up period for the model was applied before application timing. Winter cereals, as a frequently grown standard crop in middle Europe, was used as covering crop. The same scheme was performed onwards after the last strawberry season on this field in 1990.

Aquifer transport modeling At this site aquifer transport modeling has been carried out and described within an unpublished expert report [29] in the frame of a real case study for drinking water risk assessment. DMS transport modeling in groundwater at Catchment III was performed in a non-stationary way, based on the leaching entry from the strawberry field. The breakthrough curves of the two drilling profiles BK4/17 \& BK5/17 were used as time-dependent upper boundary conditions at the top of the aquifer. HYDRUS-1D leaching simulations provided the substance source of DMS for modeling the dispersion plume and dilution.

Boundary conditions of the groundwater model: The leaching of DMS under the strawberry field is calculated from the two concentration curves in leachate, which are representative of the entire field. According to the model calibration, BK5/17 represents approximately one third of the area and BK4/17 represents the remaining twothirds. Based on environmental fate data from aquifer degradation studies with DMS, ideal tracer-like transport without any degradation and retardation in the saturated zone was assumed. In addition, a mean stationary groundwater stream based on mean values from the years 2013 and 2014 was used in the model. The groundwater levels in the underlying period from 2013 to 2014 at the relevant groundwater measuring points in the vicinity of the collection system mainly show minor fluctuations of $<50 \mathrm{~cm}$. The groundwater recharge is based on an estimate of a mean annual precipitation level of $850 \mathrm{~mm}$ and a groundwater recharge of $9.4 \mathrm{l} /\left(\mathrm{s} \times \mathrm{km}^{2}\right)$ for the considered catchment area [29]. In the model, a groundwater recharge of $0.00061 \mathrm{~m} /$ day west of the groundwater collection system and upstream of the spring water collection, a value of $0.0012 \mathrm{~m} /$ day was given.

The present model covers an area of approx. $7 \mathrm{~km} \times 5 \mathrm{~km}$ and a total area of $33.9 \mathrm{~km}^{2}$. It has a model network of 10 horizontal layers with 4,360 nodes and 8,591 elements each, i.e., a total of 43,340 nodes and 85,910 elements. The mesh width ranges from approx. $15 \mathrm{~m}$ in the area of the water collection system to approx. $200 \mathrm{~m}$ in the wider surroundings (see Fig. 15). As shown in the 3D view of the model space in Fig. 14, the area under investigation is characterized by strong differences in the height of the terrain surface and deep valley incisions of the streams.

In the east, the model is delimited by a middle-sized river, which was used as a fixed potential boundary condition. On all other model boundaries (north, south and west), boundary streamlines (boundary condition of 2nd type: inflow/outflow $=0$ ) or fixed potential boundaries were defined according to the dataset of the model area. For the water collection system, an open ditch was selected in the DYNSYSTEM model and the water level at the end of the collection pipe was specified. Due to the different calculation approaches of the two programs, the water collection was represented in the current FEFLOW model by a watercourse boundary condition with specification of the water level heights and the watercourse leakage.

As another surface water body in the model area, a minor-sized stream was also represented by a water course boundary condition [29]. Figure 15 shows the water bodies and the water collection system represented in the model.

Calibration of groundwater flow: The calibration was carried out using the current average conditions. As reference values, the mean groundwater levels in the period 2013/2014 were taken as a basis and compared with the 


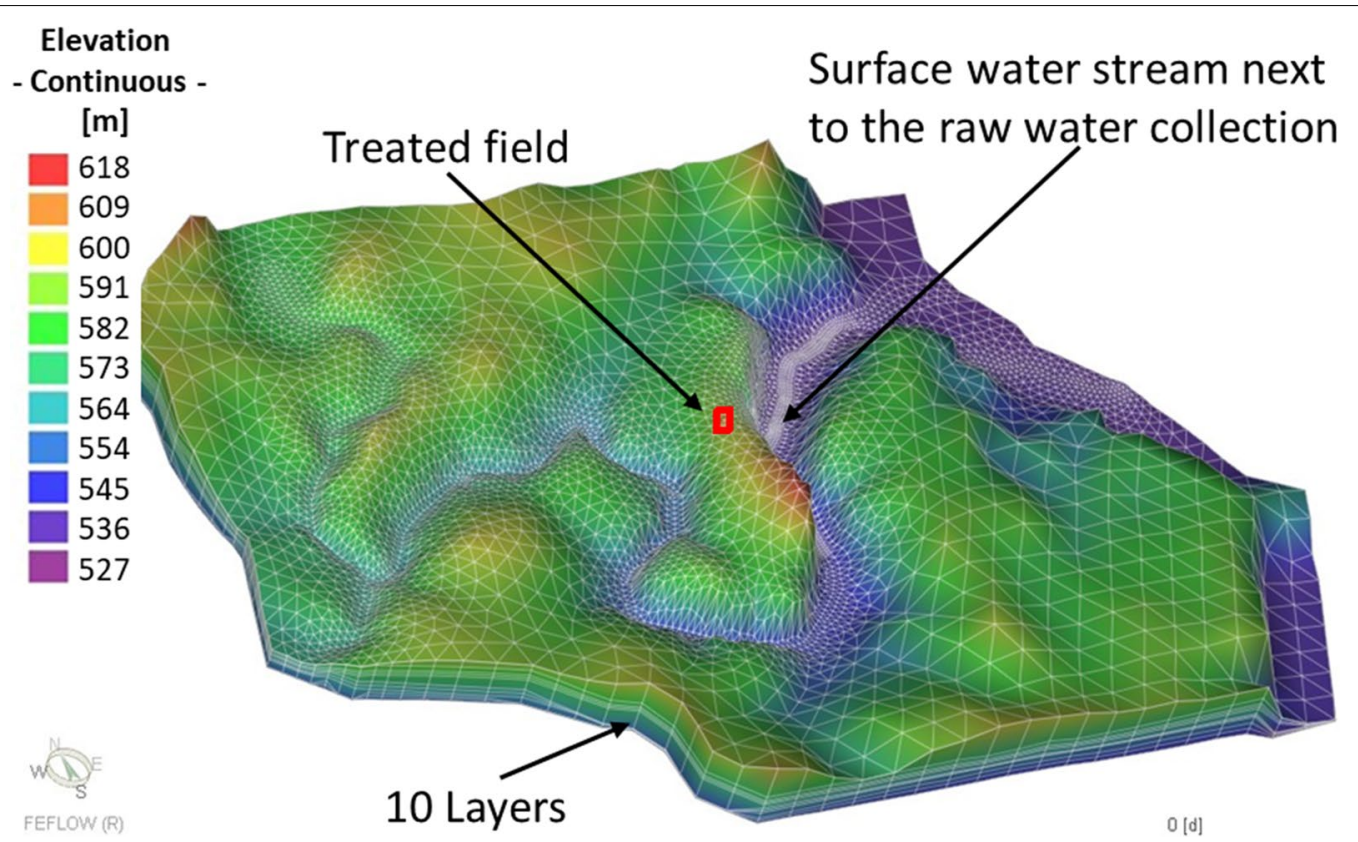

Fig. 14 3D representation of the model space including terrain surface (tenfold elevated view) (based on unpublished expert report [29])

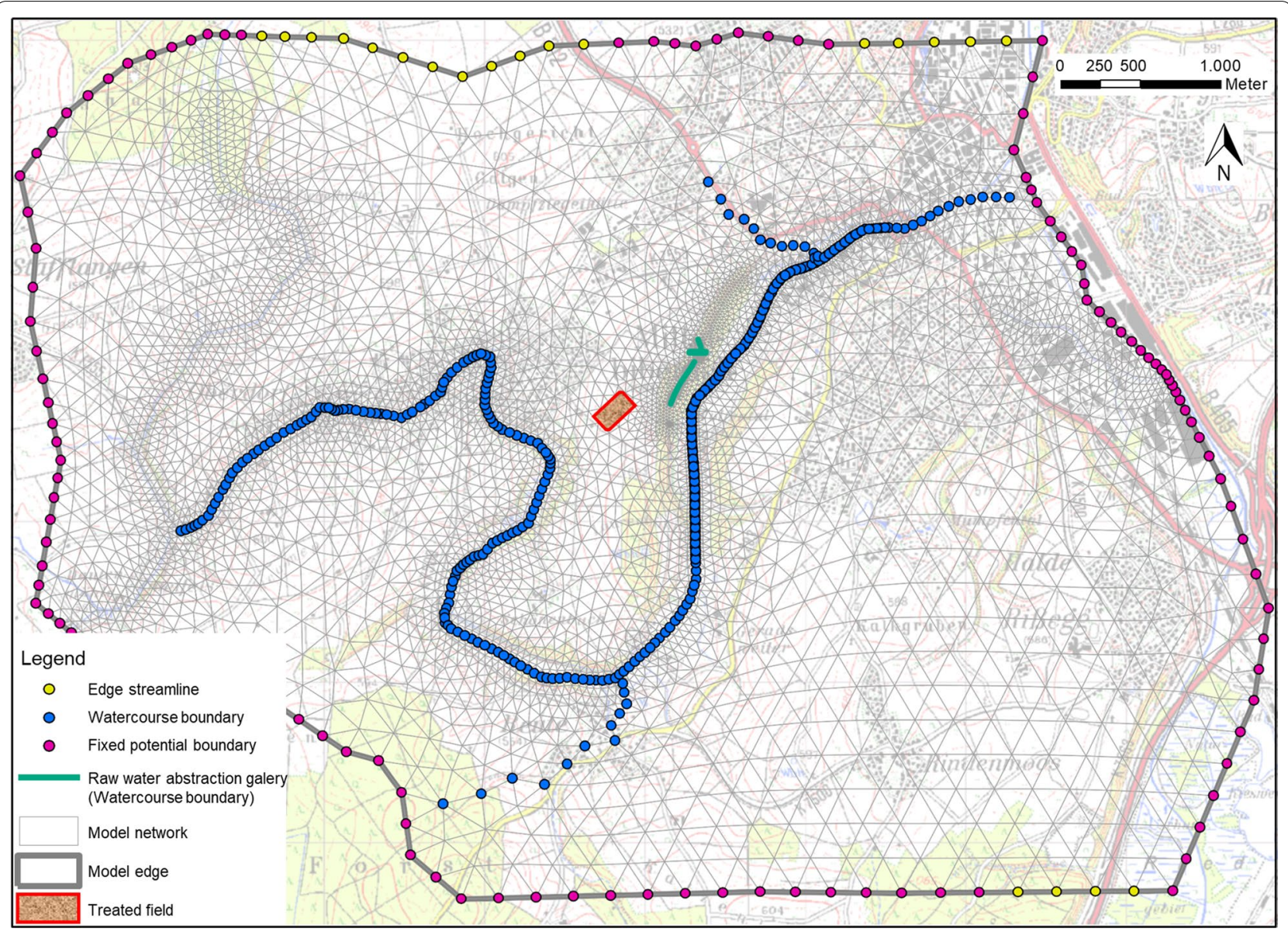

Fig. 15 Overview of groundwater model: model network and boundary conditions (based on unpublished expert report [29]) 


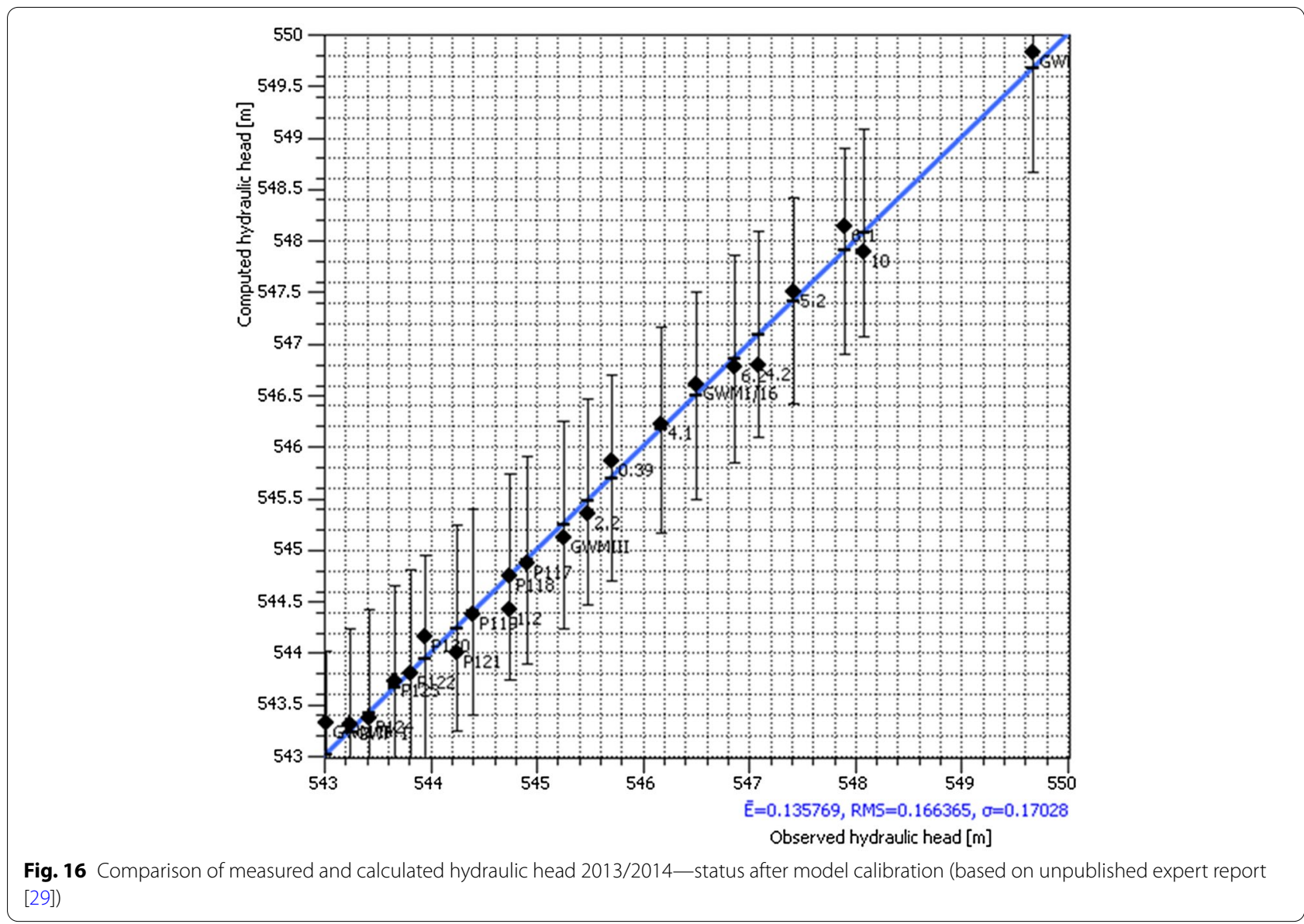

calculated values. In the course of the calibration, the hydraulic conductivity values of individual layers and the leakage factors of the stream were varied slightly locally in order to achieve a good agreement between the calculated and measured groundwater levels.

The result of the model calibration 2013/2014 shows a very good agreement between the calculated and the measured groundwater levels as shown with a mean absolute deviation of approx. $0.17 \mathrm{~m}$ and a standard deviation $(\sigma)$ of $0.17 \mathrm{~m}$ (see Fig. 16).

Transport modeling in aquifer: Based on the adapted groundwater flow model, a transport model was set up in the next step to simulate the unsteady distribution of DMS from the strawberry field towards the water collection system. The basis was the mean stationary groundwater flow based on the model calibration and further boundary conditions, as mentioned in "Boundary conditions of the groundwater model" of Catchment III under "Methods" section. Moreover, for the scale-dependent parameter (dispersivity), which is decisive in tracer transport, a longitudinal dispersivity of $30 \mathrm{~m}$ (transverse dispersivity: $0.3 \mathrm{~m}$ ) was chosen. This assumption is a benchmark, based on Gelhar (1992) [35], where a number of determined dispersivities versus their scale of observation were analyzed as metadata. Since the data originate from many field sites, which are widely differing in the characterization of their geological material, the provided range was deemed to cover the situation in Catchment III. That is why a value estimated from this study was considered applicable as a standard starting value for the calculation of dispersion.

The calculated breakthrough curves were applied to all model nodes at the groundwater surface, below the strawberry field, as a boundary condition for mass supply in the solute transport model. Background concentrations were not measured in significant amounts in the concerned parts of the catchment area. Therefore, at all other model 
Table 4 Compact summary of Catchment III

\begin{tabular}{|c|c|c|c|}
\hline \multicolumn{4}{|l|}{ Crops and use history } \\
\hline Treated crops & \multicolumn{3}{|l|}{ Strawberries } \\
\hline Application & \multicolumn{3}{|c|}{ 1980-1990; application in late spring and summer, BBCH growth stages > 60} \\
\hline \multicolumn{4}{|l|}{ Observation } \\
\hline Leachate sampling & \multicolumn{3}{|c|}{ Matrix water samplings (mixed of 5 m sections) from drilling material of a bore, November 2017} \\
\hline Position of monitoring wells & $\begin{array}{l}\text { Immediately next to the treated field } \\
\text { (downstream side) }\end{array}$ & Close to the raw water abstraction & Raw water collection gallery \\
\hline $\begin{array}{l}\text { Distance of treated area to downstream } \\
\text { monitoring wells }[\mathrm{m}]\end{array}$ & $\sim 5$ & $\sim 150-300$ & $\sim 200-320$ \\
\hline \multicolumn{4}{|l|}{ Geology/Lithology } \\
\hline Leaching profile & \multicolumn{3}{|c|}{$\begin{array}{l}\text { Luvisol of loess loam covering quaternary glacial deposits (mainly silt/marl and gravel); partly as conglom- } \\
\text { erates, }\end{array}$} \\
\hline Aquifer & \multicolumn{3}{|c|}{ Quaternary high terrace gravel from Riß Ice Age (Dietmanns-formation) } \\
\hline Basement & \multicolumn{3}{|c|}{ Tertiary Upper Freshwater Molasse } \\
\hline Location & \multicolumn{3}{|l|}{ Southern Germany, Upper Swabia } \\
\hline Topography & \multicolumn{3}{|c|}{ Field is located on an elevation, which is looped by a stream; slope is $1.5^{\circ}$; agricultural land use } \\
\hline \multicolumn{4}{|l|}{ Aquifer properties } \\
\hline $\begin{array}{l}\text { Groundwater level below treated field } \\
{[\mathrm{m}]}\end{array}$ & \multicolumn{3}{|l|}{$39.9-47.5$} \\
\hline Thickness [m] & \multicolumn{3}{|l|}{$\sim 10$} \\
\hline Slope of aquifer $[\mathrm{m}] /[\mathrm{m}]$ & \multicolumn{3}{|l|}{$2 / 300$} \\
\hline Hydraulic conductivity [m/d] & \multicolumn{3}{|l|}{$43-86$} \\
\hline $\begin{array}{l}\text { Dispersivity (longitudinal/vertical) }[\mathrm{m}] \\
{[\mathrm{m}]}\end{array}$ & \multicolumn{3}{|l|}{$30 ; 0.3$} \\
\hline \multicolumn{4}{|l|}{ Used models } \\
\hline Leaching modeling & \multicolumn{3}{|l|}{ PEARL and HYDRUS-1D } \\
\hline Aquifer transport modeling & \multicolumn{3}{|l|}{ FEFLOW } \\
\hline
\end{tabular}

areas outside the strawberry field, the DMS source concentration was set to zero.

Catchment III-compact summary The main facts regarding Catchment III are presented in Table 4. A concise overview about the environmental conditions and basics of the site-specific modeling approach is provided there.

\section{Natural attenuation}

In this section, partial results of the three study sites (i.e., the development of DMS concentrations in leachate and aquifer) are compared and described. Although the conditions and results are different at each site, comparable steps in the attenuation according to the position in the catchment of a raw water abstraction system could be identified. Steps of attenuation, which are available at the concerned sites in a comparable format are:

1. Simulated concentration in the leachate at $1 \mathrm{~m}$ depth;

2. Simulated concentration in the leachate at the breakthrough to groundwater;
3. Measured and/or simulated concentration at a monitoring well directly next to the treated area;

4. Measured and/or simulated concentration at monitoring wells close to the treated area, with exception of Catchment III;

5. Measured and/or simulated concentration at monitoring wells close to the raw water abstraction;

6. Concentration in raw water was additionally taken into account, because water flow at the study sites is not significantly affected by activities of the water supplier and no other major DMS sources were detected. Minor background concentrations were not considered.

Since the conditions at the three study areas are very different, a simple approach was chosen to quantify the reduction of DMS concentrations. A factor of attenuation was directly calculated from the DMS concentration at one step to the related next step. For this stepwise attenuation approach, the time delay of the concentration curves due to the corresponding velocity of the dispersion plume was reflected. Therefore, relatively stationary high concentrations according to use history were 


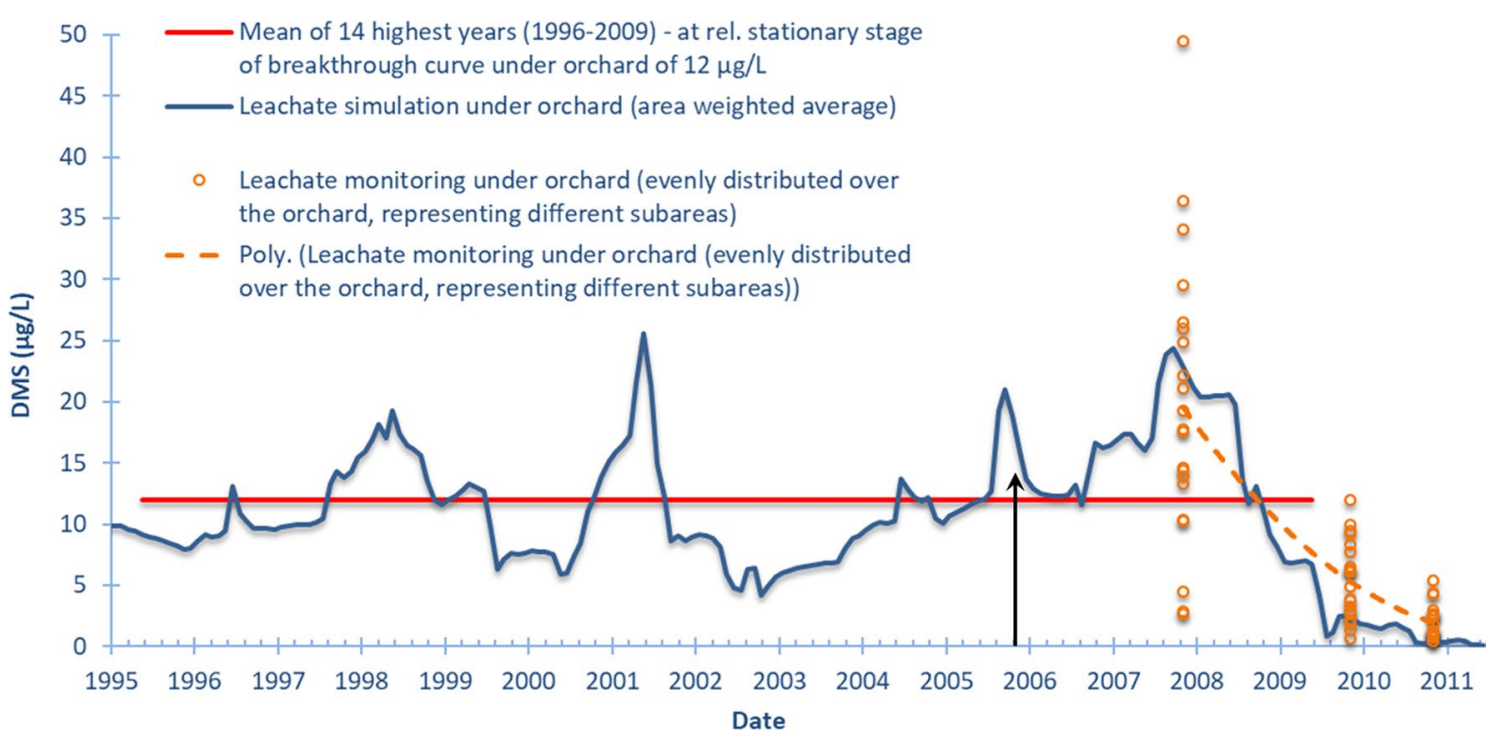

Fig. 17 Simulated breakthrough vs. observed DMS concentration in leachate at the hydraulic head of the aquifer; vertical arrow marks the time of last DMS entry to soil

followed over time and distance to allow for a good comparison.

\section{Results}

Results of DMS concentration along the subsurface flow paths based on modeling and monitoring are presented as partial results of each study site. Considering the overall focus of the study on the aspect of natural attenuation, the partial results were subsequently merged. The determined values of a natural attenuation of the DMS concentration under real conditions are presented in the "Final results on natural attenuation" under "Results" section.

\section{Partial results on study site Catchment I-Rhein-Ruhr Region \\ Leaching}

The leaching simulation from the PEARL model against the measured DMS concentrations in leachate is presented in Fig. 17. There, the course of the breakthrough curve shows an area weighted mean concentration below the orchard. Probably, the strong fluctuation of the course is mainly reasoned by changes within the use history and climatic conditions. The leachate sampling points were evenly distributed over the orchard and represent different subareas of the orchard. Measured concentrations in the leachate scatter in a wide range, what can be also explained by the divers use history of the several plots (see Fig. 3). Since both datasets-measured and simulated-match visually well, the simulation was considered reliable and no further calibration was carried out. A mean concentration over a duration of 14 years, according to the use history, gives a relatively stable high concentration of $12 \mu \mathrm{g} / \mathrm{L}$. This mean concentration is almost identical with the 14-year mean at $1 \mathrm{~m}$ depth, but with a time delay of approx. 2 years. At around 5 years after last application of EUPAREN M, DMS leached almost completely from the vadose zone.

The standard FOCUS scenario Hamburg, which is used in a regulatory context in Germany and other EU countries, led to slightly lower PECgw values for DMS of $9.4 \mu \mathrm{g} / \mathrm{L}$ compared to the local scenario. The higher seepage flow in the Hamburg scenario, which increases dilution of the concentration in the leachate, could be an explanation.

\section{Transport in aquifer}

The transport simulation from the HYDRUS 2D model against the measured DMS concentrations at related groups of monitoring wells is shown in Fig. 18. Under the orchard the aquifer simulation is in line with shallow groundwater monitoring data until approx. 2012 (Fig. 18a). The reason for the relatively stable plateau concentration at about $0.1 \mu \mathrm{g} / \mathrm{L}$ as evidenced by the monitoring data until 2016, is unclear. One reason could be a still continuously remaining leaching event on a minor level. Furthermore, an existing regional DMS background concentration in the groundwater coming from other sources in the catchment, upstream of the orchard, could also be an explanation. Potential sources of the existing background concentration of DMS could be reasoned by home and gardening uses or not well-documented uses 

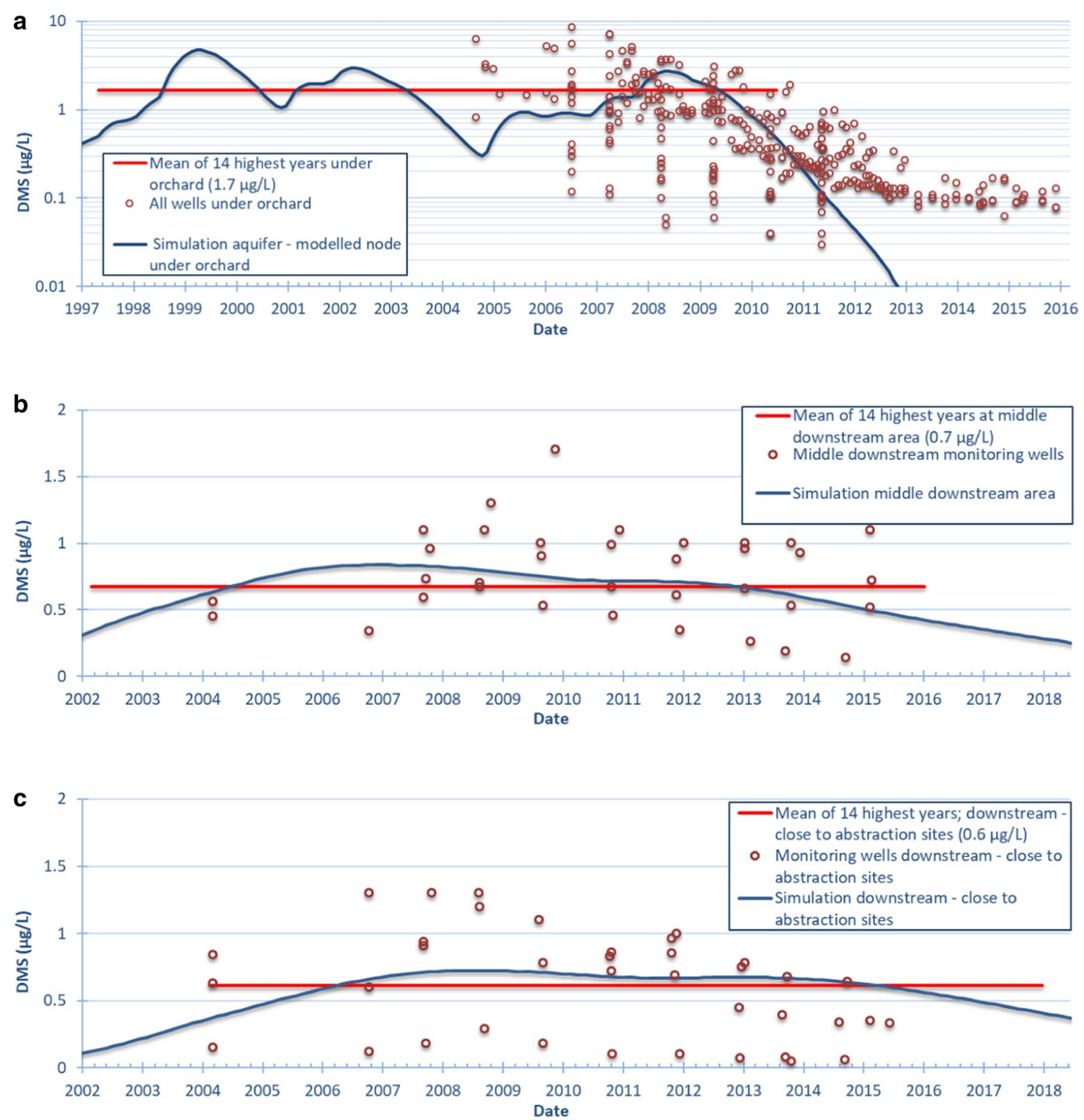

Fig. 18 Observed vs. simulated DMS concentrations in the groundwater aquifer $\mathbf{a}$ under orchard, $\mathbf{b}$ at middle downstream area, $\mathbf{c}$ downstreamclose to abstraction sites

of tolylfluanid and dichlofluanid degrading to DMS by a farmer applying in the catchment. This applies in the case of all three evaluated study sites. A mean concentration over the 14 years corresponding to use history of $1.7 \mu \mathrm{g} / \mathrm{L}$ was determined.

The datasets of the monitoring well groups from the downstream area, and the related nodal monitoring output also match visually well, and can be considered reliable (Fig. 18b, c). Following the breakthrough curve, the long-term variability of concentration below the orchard results mainly from the local climatic conditions and variabilities in the usage history at the site and soil conditions, too. A mean DMS concentration of $0.7 \mu \mathrm{g} / \mathrm{L}$ over a duration of 14 years in the middle downstream monitoring well line $(1,200 \mathrm{~m}$ upstream) at the relatively stable stage was calculated. At the downstream monitoring wells, close to the raw water abstraction galleries, a mean concentration of $0.6 \mu \mathrm{g} / \mathrm{L}$ was predicted. DMS concentrations in the aquifer slowly decline and reach background level around 2020. Compared to 1st line of monitoring wells (600 $\mathrm{m}$ upstream), the breakthrough curve is shifted by one to two years. An overall spotlight on the 


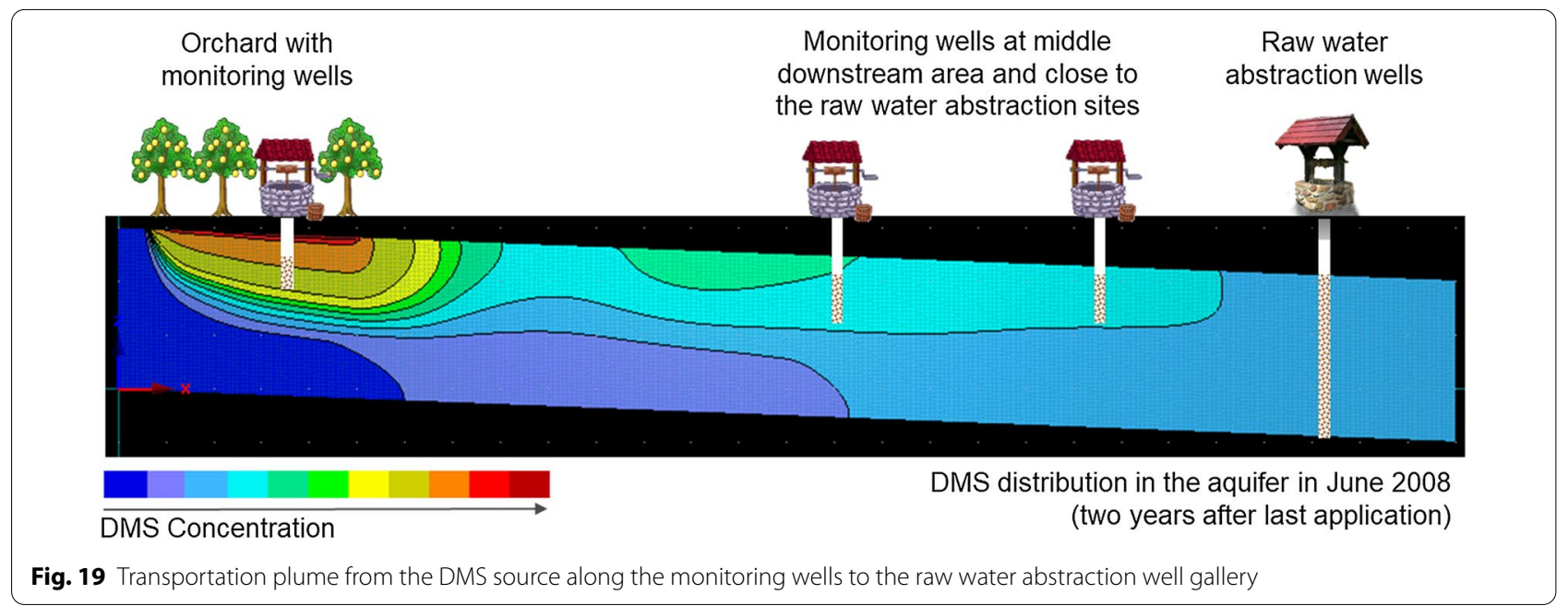

determined attenuation of DMS from its source to the raw-water abstraction will be set in "Final results on natural attenuation" section.

The transect overview in Fig. 19 is generated from a HYDRUS 2D simulation and shows an example of the distribution of the DMS plume in the aquifer two years after the last application of tolylfluanid. As expected, DMS behaves like an ideal tracer. A distinct vertical distribution of DMS concentrations is observed. This vertical gradient is driven by different conductivity levels in the upper and lower aquifer, and by limited longitudinal dispersivity and convection. Shallow monitoring wells at the middle downstream area can therefore slightly overestimate the average DMS concentrations in the aquifer. Complete mixing or homogenization of concentrations can only be observed at a distance of more than $2 \mathrm{~km}$.

A DMS concentration in abstracted raw water could also be taken into account at this site. According to an unpublished expert report [17], for pragmatic reasons, considering changes in actual abstraction rates were omitted. In the longer term, this aspect is of less importance for the forecast of substance transport, as the transport speed is more influenced by the gradient and less by the absolute level of the groundwater level.

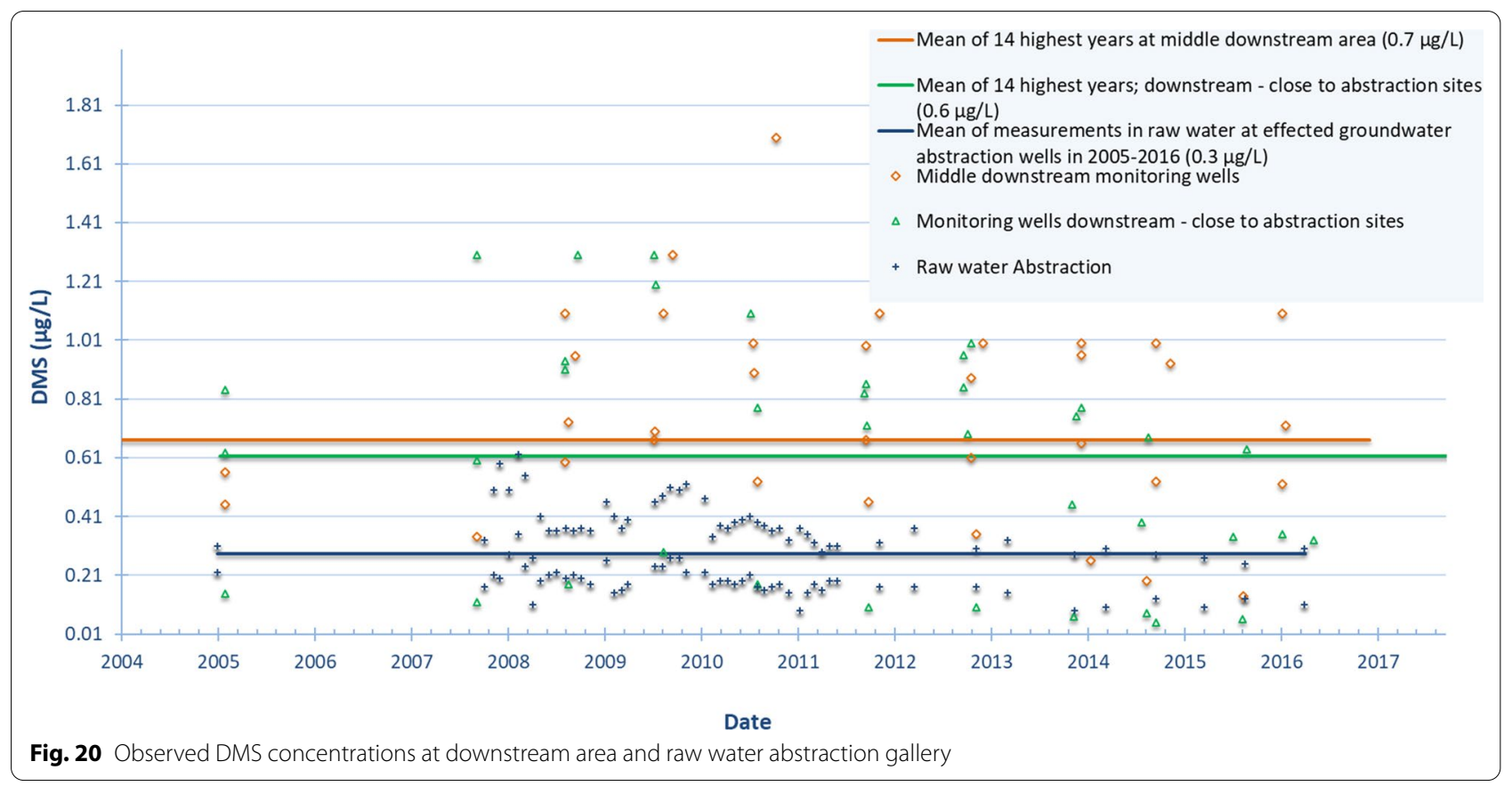


Disregarding the flow rate fluctuations caused by raw water abstraction activities, the mean concentration between the years 2005 to 2016 was considered reliable to be compared with the related measurements conducted downstream-close to the raw water abstraction. A mean DMS concentration of approx. $0.3 \mu \mathrm{g} / \mathrm{L}$ in abstracted raw water from the abstraction well gallery was detected over this time (Fig. 20).

An observed background concentration as mean value from non-affected local monitoring wells with concentrations > LOQ is only available out of the year 2011. This estimated value of approx. $0.055 \mu \mathrm{g} / \mathrm{L}$ is a significant concentration. But in relation to the measured and simulated concentrations at the affected monitoring and abstraction wells, it is only minor and is therefore not considered in this study. However, it may provide an explanation for the aforementioned plateau concentration of DMS in the aquifer.

\section{Partial results on study site Catchment II-Lower Rhine Bay Leaching in soil and transport in aquifer}

The leaching simulation through the vadose zone obtained from the PEARL model as well as measured DMS in the aquifer is presented in Fig. 21. Time-overlapped simulations and measured data are not available at this site. The dataset follows the course of attenuation over both, time and distance. The observations made in 2006 at the abstraction wells show the related and attenuated maximum concentrations at the simulated breakthrough curve from the preceding years.

By extending the application period throughout the five preceding years, the overall breakthrough curve could be straightened considerably. Using this approach, the curve is more representative for real conditions at the transition zone from vadose to saturated section. This makes results from a relatively short application period more robust, because the influence of individual very exceptional constellations of annual percolation is less important. According to the use history, five years is the approximate duration of relatively stable high concentrations. From a relatively constant mean concentration at $1 \mathrm{~m}$ depth of approx. $13.6 \mu \mathrm{g} / \mathrm{L}$ the delay to the equivalent stage on the breakthrough curve at $9.5 \mathrm{~m}$ depth is approx. four years. The corresponding DMS concentration at the breakthrough from vadose zone to the groundwater aquifer is slightly higher and amounts to approx. $14.7 \mu \mathrm{g} / \mathrm{L}$. For the monitoring well observing the upper part of the aquifer next to the treated area (16-172) a total delay of approx. five to six years after the last application of dichlofluanid can be assumed. So, the first one to two years with observed DMS concentrations of $3.6 \mu \mathrm{g} / \mathrm{L}$ in the aquifer is assumed to show the end of the relatively stable stage with highest concentrations in the vadose zone.

An additional simulation was performed using the standardized FOCUS scenario Hamburg, which is used in a regulatory context in Germany and other EU countries. A resulting conservative DMS PECgw of $17.9 \mu \mathrm{g} / \mathrm{L}$ at $1 \mathrm{~m}$ depth was calculated (Fig. 21).

In the contamination plume of the aquifer, a total delay of only 0.5 to 1 year is assumed according to an unpublished expert report [25] (see also Fig. 9). Based on this total delay, a stepwise time offset of four months for each distance step was used for optical presentation of mean values. About $200 \mathrm{~m}$ further downstream, a monitoring well of the upper aquifer (16-102) shows a DMS concentration of $1.8 \mu \mathrm{g} / \mathrm{L}$ for the year 2007 (mean of 2006-2008).

To quantify a comparable DMS concentration in the aquifer at the monitoring wells on the middle downstream area $(\sim 400 \mathrm{~m})$, a mean DMS concentration was measured at $1.1 \mu \mathrm{g} / \mathrm{L}$. This mean value was calculated for the years 2006 to 2008 .

Measurements of lower DMS concentrations closer to the raw water abstraction wells are probably highly influenced by the locally ubiquitous background concentration of $>0.1 \mu \mathrm{g} / \mathrm{L}$ of the last years. Since there were DMS concentrations measured at positions, where an immediate influence of the considered orchard can be excluded, there must have been other sources, generating background concentration. The simulated flow paths (Fig. 9) were taken into account and upper filter streams were excluded, to consider only the influence from other point sources.

Therefore, an exact quantification of lower DMS concentrations at such positions on the downstream area and at the abstraction wells using measured concentrations is nearly impossible. Moreover, the amount of abstracted water at the water treatment plant should be taken into account for a more precise determination of its effect on the DMS concentration. In the related expert report [25], it was concluded that if the existing water rights were to be exhausted, which would mean an increase of up to $13 \%$ of the current flow rate, this would have an insignificant impact on the groundwater situation. Since the annual abstraction amount was continuously contrarily reduced by $15 \%$ on average ( $\max .37 \%$ ) in relation to the year 2005, the effect of this reduction needed to be considered. An estimation of the concentration in raw water $\left(\mathrm{c}_{\mathrm{rw}}\right)$ at the affected well was conducted using Eq. 2 (based on [36]). In this calculation the concentration of 


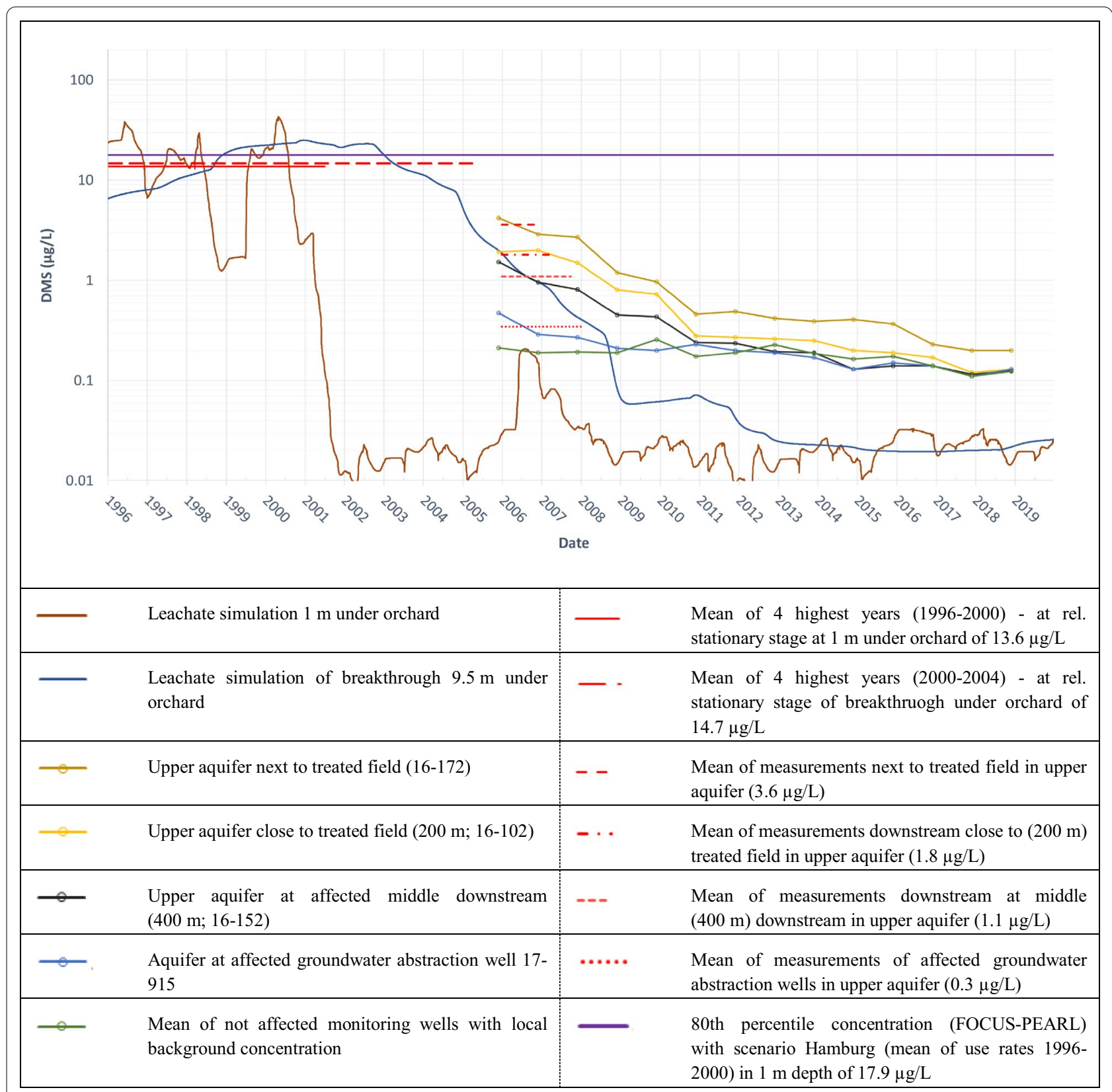

Fig. 21 Simulated DMS concentration in leachate in $1 \mathrm{~m}$ depth and at the hydraulic head of the aquifer (approx. $9.5 \mathrm{~m}$ depth) followed by stepwise per distance observed DMS concentration in the aquifer (dots mark measured DMS concentrations)

DMS in the leachate $\left(\mathrm{c}_{\text {leach }}\right)$ at breakthrough to the aquifer was multiplied with a dilution factor, relating the annual groundwater recharge $\left(\mathrm{gw}_{\text {rechargeVol. }}\right)$ under the field to the total annual raw water abstraction volume at the well $\left(\mathrm{rw}_{\mathrm{abstractionVol}}\right)$. For the additional abstracted water volume, the local background concentration $\left(\mathrm{c}_{\mathrm{bkg}}\right)$ was estimated from the average measured concentration at not affected monitoring wells outside the downstream zone of the treated field. Over the considered years
(2006-2019), the measured concentrations in raw water amounted to a low level of 0.47 to $0.11 \mu \mathrm{g} / \mathrm{L}$. The annual groundwater recharge originating from the treated field was taken from the leaching simulation and amounted to a range between 9,156 to $38,916 \mathrm{~m}^{3} / \mathrm{a}$ (av. 20,962 $\mathrm{m}^{3} / \mathrm{a}$ ). Raw water was abstracted at the affected well in a total range from $1.09 \times 10^{6}$ to $0.69 \times 10^{6} \mathrm{~m}^{3} / \mathrm{a}$. A time offset of two years from the simulated leachate concentrations, 
next to the treated field to the raw water abstraction wells was included in the calculation.

$$
c_{r w}=\frac{c_{\text {leach }} \times g w_{\text {rechargeVol. }}+c_{b k g} \times\left(r w_{\text {abstractionVol. }}-g w_{\text {rechargeVol. }}\right)}{r w_{\text {abstractionVol. }}}
$$

As a result, the calculated to the measured concentrations in raw water of the years 2006-2019 had an average correlation of 1.01 (0.61 to 1.30). For testing the influence of a changing amount of raw water abstraction, this calculation was also performed with a constant mount of abstracted raw water from 2005 . The result with an average correlation of also 1.01 ( 0.62 to 1.31 ) was very similar. Surface water bodies nearby the study site were not taken into account, but their influence on the natural attenuation at this site is possible and probable, as well.

Neglecting the flow rate fluctuations caused by raw water abstraction activities, a mean concentration between the years 2006 to 2008 was considered reliable when compared with the related values in the middle of the downstream area. Hence, a mean DMS concentration in the affected raw water abstraction well of approx. $0.34 \mu \mathrm{g} / \mathrm{L}$ was determined during this time (Fig. 21).

The continuously higher DMS concentrations in the raw water samples of the affected abstraction well than in the local background until 2008 indicate the influence of the DMS entry from the area of concern. Looking on the difference between DMS concentration in raw water and local background concentration in the catchment, it can be assumed that leaching from the treated area increases the concentration in raw water by approx. $0.26 \mu \mathrm{g} / \mathrm{L}$ at measured maximum (Fig. 22). After year 2008, the DMS concentration in abstracted raw water is dominated by a local background concentration based on entries from other sources.

For the determination of a local background concentration, only DMS detections from filter screen units in the lower aquifer were considered. The upper filter sections reflect small-spatial differences in groundwater recharge very distinct, but not the general background concentration, as shown in "Mixing within aquifer to raw-water abstraction in Catchment II" under "Results" section.

\section{Mixing within aquifer to raw-water abstraction in Catchment \\ II}

The calculated flow directions between the field and the affected wells are depicted in Fig. 9. The flow time of water between two arrows amounts to 30 days. Therefore, it takes approximately one to two years for the groundwater in the aquifer under the treated field to reach the mainly affected abstraction well.

With consideration of measured concentrations in the different depths of the filter screens in each pair of wells, an increasingly homogeneous mixing of leached DMS with distance becomes obvious (Fig. 23). Graph a) shows a high concentration gradient between the upper quarter of the aquifer and the lower part amounting to a factor between 3 and 5 from 2006 to 2008. However, a partial mixing of the leachate below the orchard into deeper parts of the aquifer can be observed with the highest concentrations in the lower aquifer from the years 2006 and

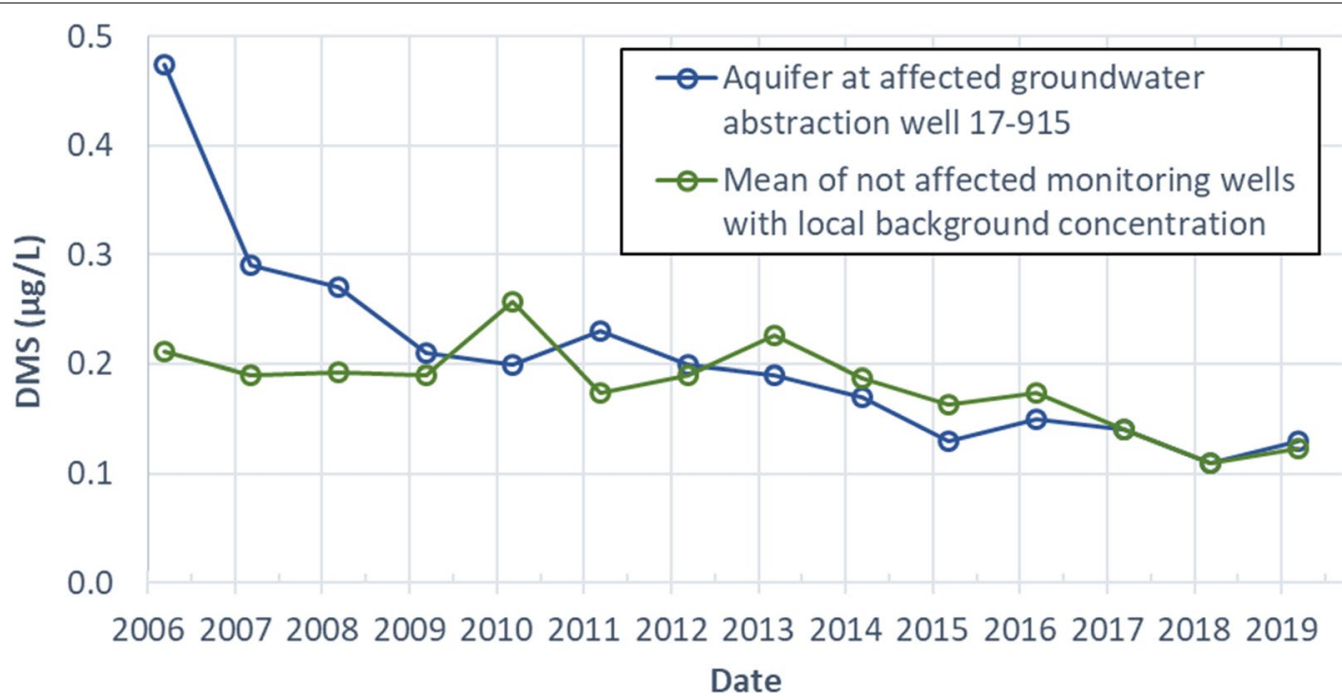

Fig. 22 Observed DMS concentration in the affected raw water abstraction wells compared to not affected monitoring wells with background concentration in Catchment II 


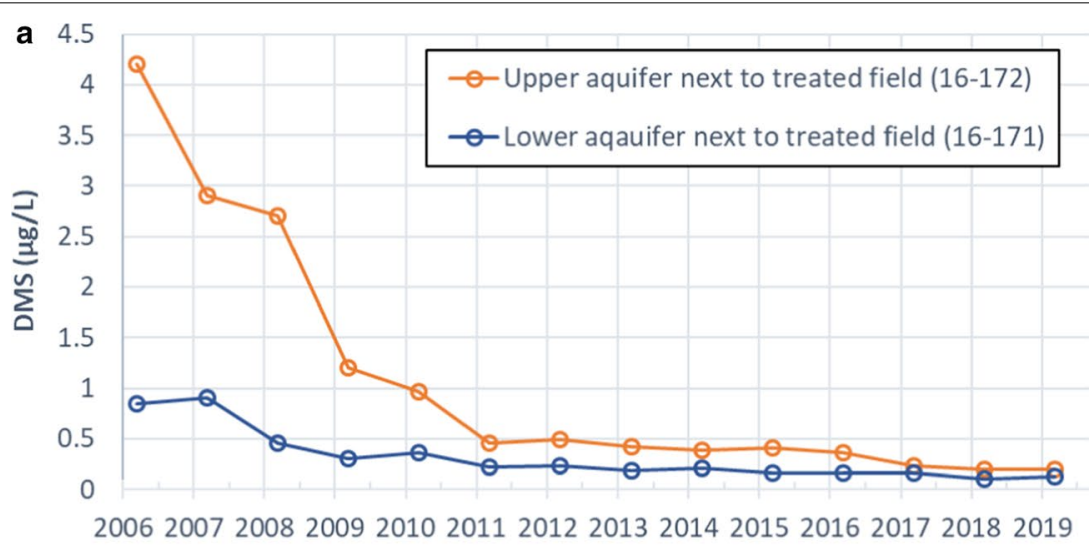

Date
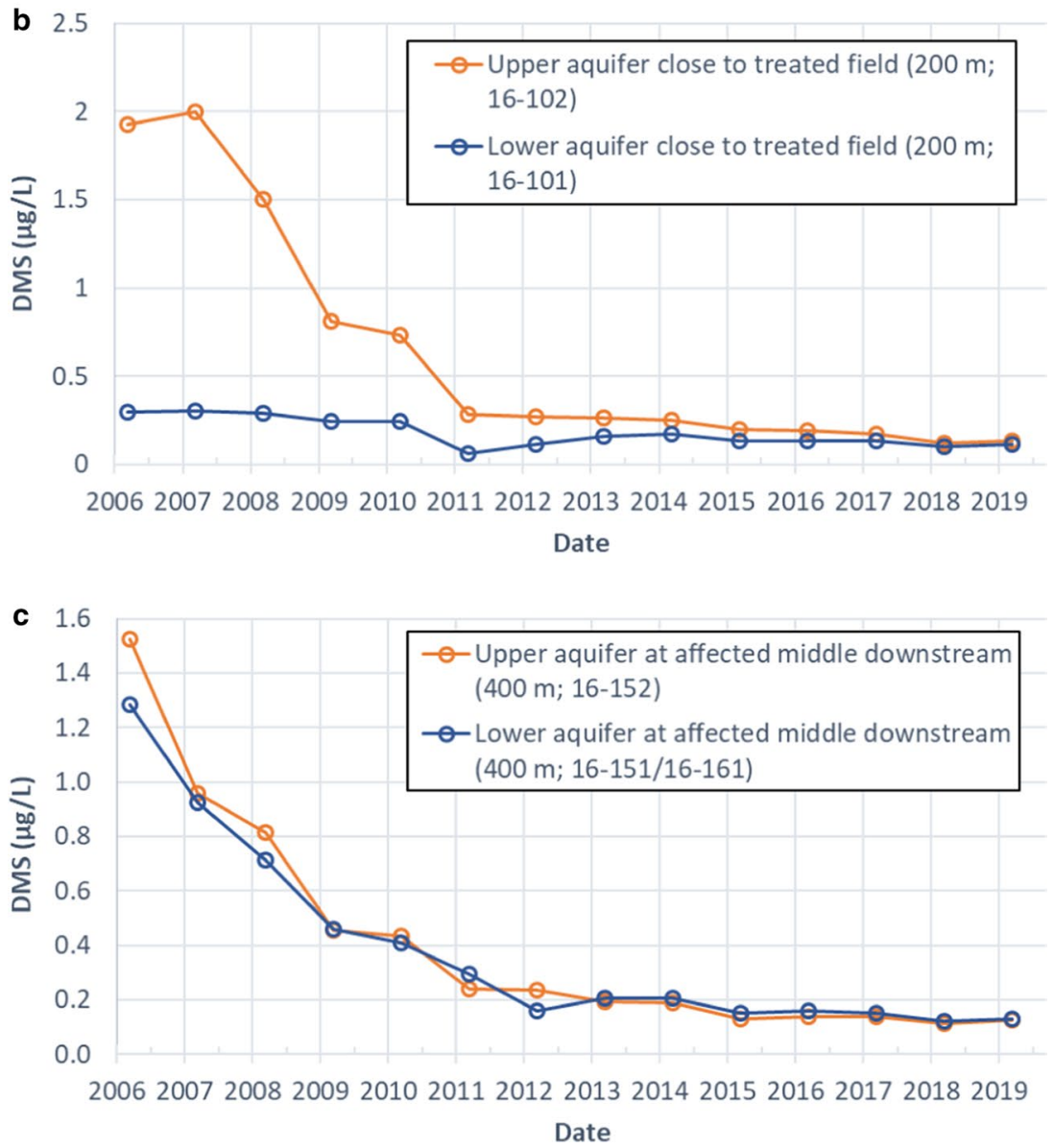

Fig. 23 Measured values in a stepwise overview on DMS mixing in the groundwater stream in the area of concern at Catchment II 


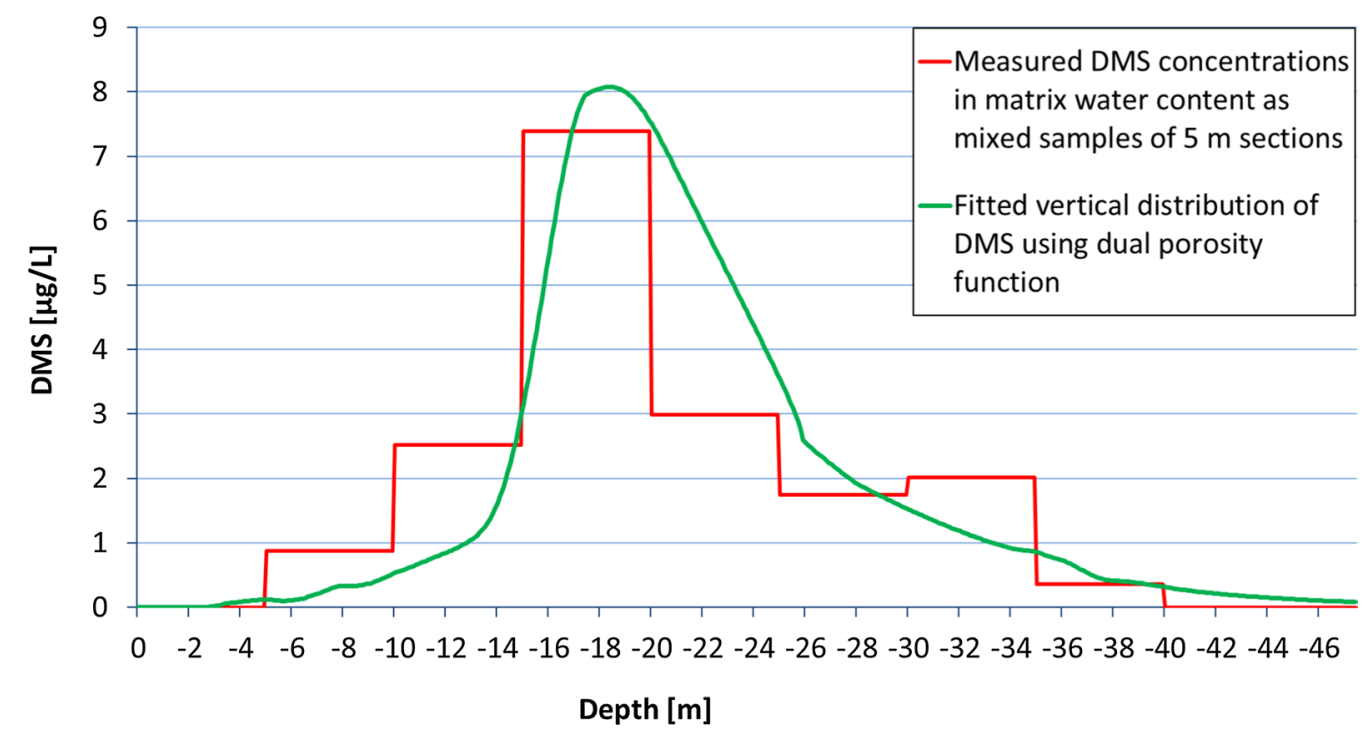

Fig. 24 Curve of DMS concentration distribution over depth, calibrated to measured concentrations from bore BK4/17 on north-east strawberry field in Catchment III

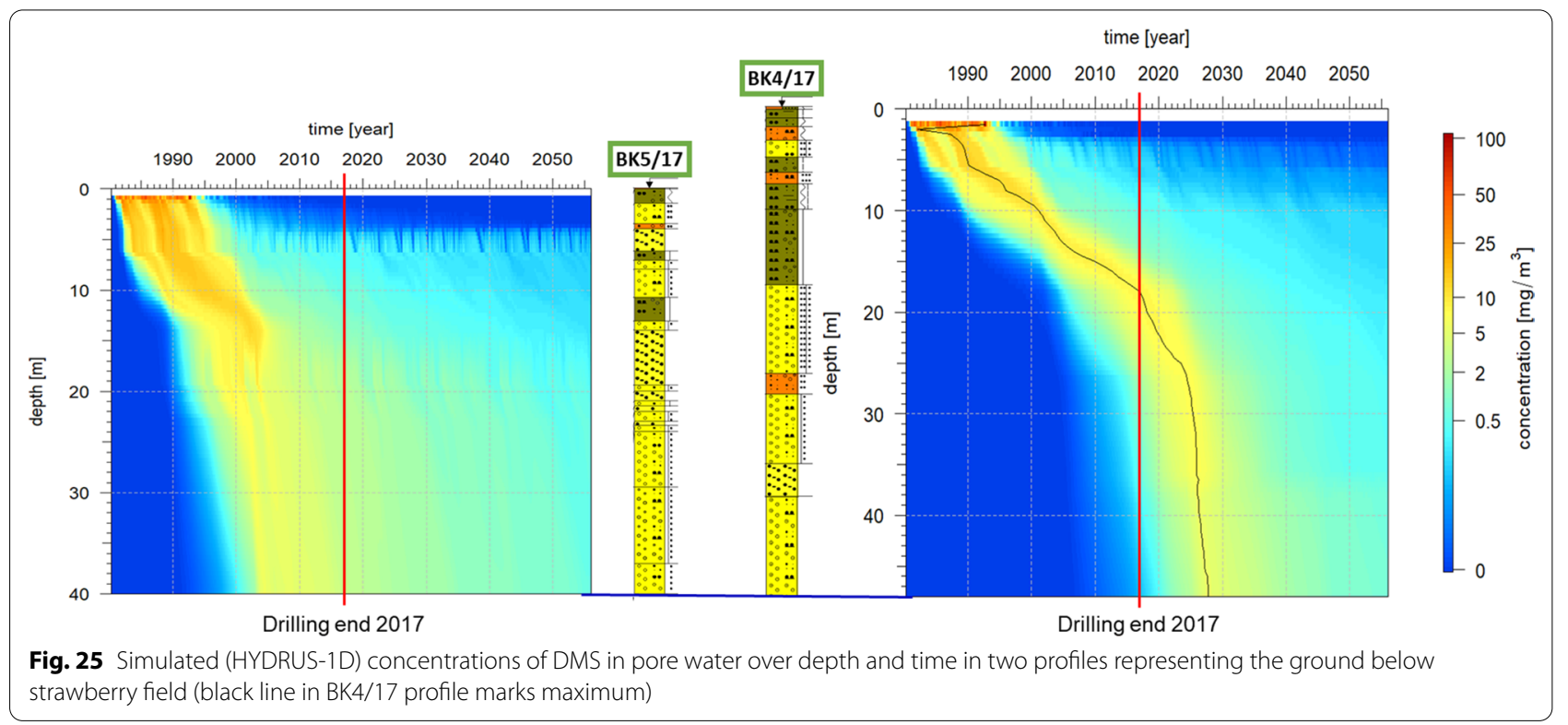

2007 being considerably above the background concentration (compare Fig. 22).

This gradient was not observed that clear at the pair of monitoring wells next in line $\sim 200 \mathrm{~m}$ further downstream $($ graph $b)$ ). Probably this is caused by dilution effects in the aquifer. Nevertheless, a substantial difference between DMS concentrations from the upper and lower aquifer parts becomes apparent at this distance (factor 6 to 7 from 2006 to 2008).
Graph c), representing the situation $\sim 400 \mathrm{~m}$ downstream from the orchard, shows dilution as well as uniform vertical mixing of the leached DMS within the aquifer at this distance. Concentrations in the upper and lower parts of the aquifer are nearly completely equalized. 


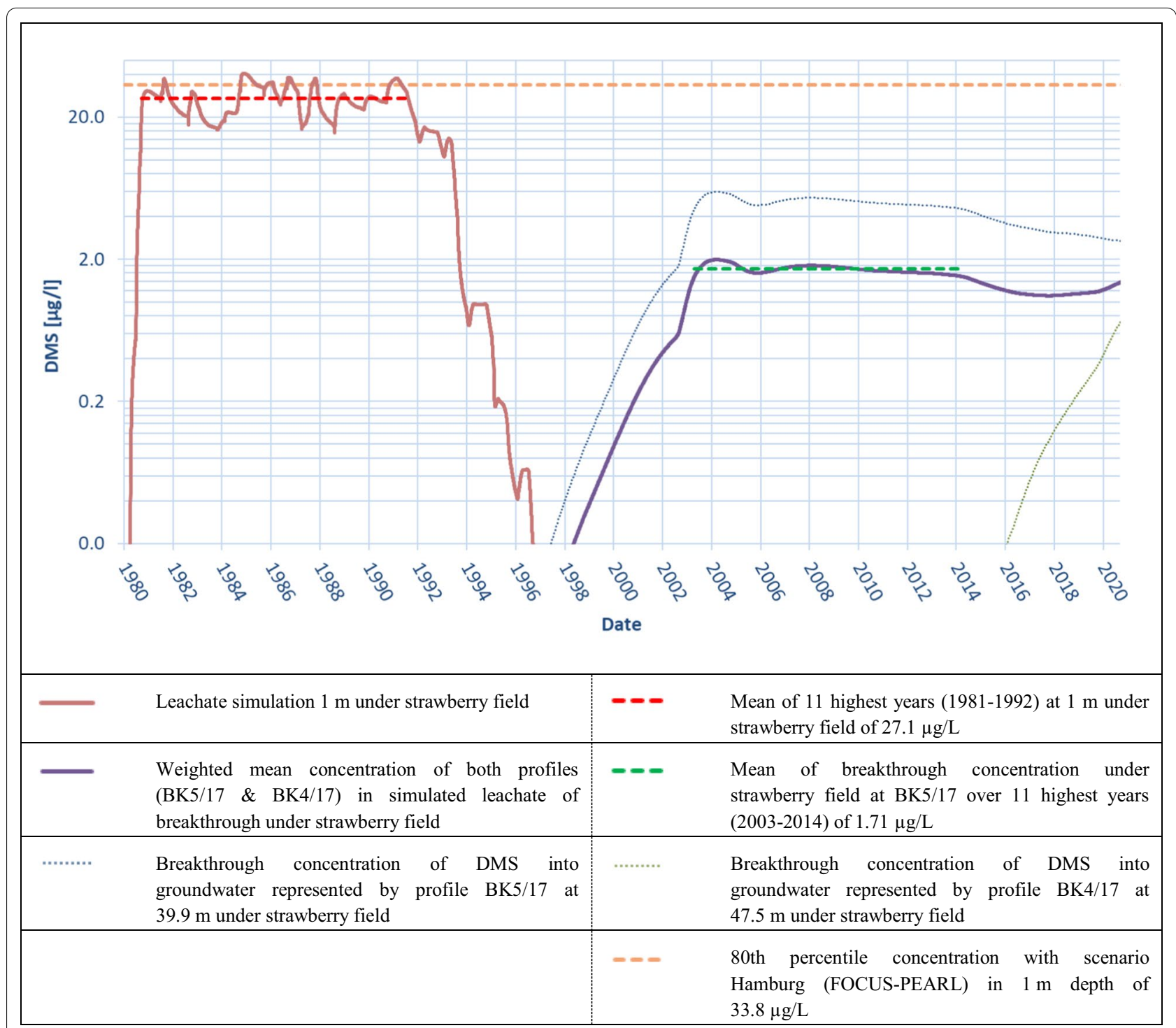

Fig. 26 Simulated DMS concentrations in leachate at $1 \mathrm{~m}$ depth and at the hydraulic head of the aquifer (39.9 $\mathrm{m}$ depth)

\section{Partial results on study site Catchment III-Upper Swabia Leaching}

The resulting concentration curve of DMS in the pore water over depth at the time of sampling from the borehole BK4/17 (Nov. 2017) is shown in Fig. 24. Since observed and simulated concentrations matched visually well, the simulation has been regarded reliable. The maximum simulated concentration in the pore water amounted to $8 \mu \mathrm{g} / \mathrm{L}$ compared to $7.4 \mu \mathrm{g} / \mathrm{L}$ as measured concentration. The parameterization of the transport behavior of DMS from this profile was carried over to the second profile BK5/17. In this profile, no DMS was detected during the analysis.
Figure 25 provides an overview of the simulated distribution of DMS in pore water over depth and time. The red line marks the time of sampling of DMS residues in the borehole of BK4/17. And the black line highlights the course of maximum concentration. In the part of the field represented by BK5/17, DMS leached earliest to groundwater. According to the visualized breakthrough, DMS would have been discharged into groundwater here since the end of the 1990s. At this time, the major amount had already been leached out there. But from parts of the field represented by bore BK4/17, DMS is only in 2020 beginning to leach in significant amounts. There, the maximum concentration in the leachate of approx. $5.2 \mu \mathrm{g} / \mathrm{L}$ is expected to be reached only in the years $2027 / 2028$. 


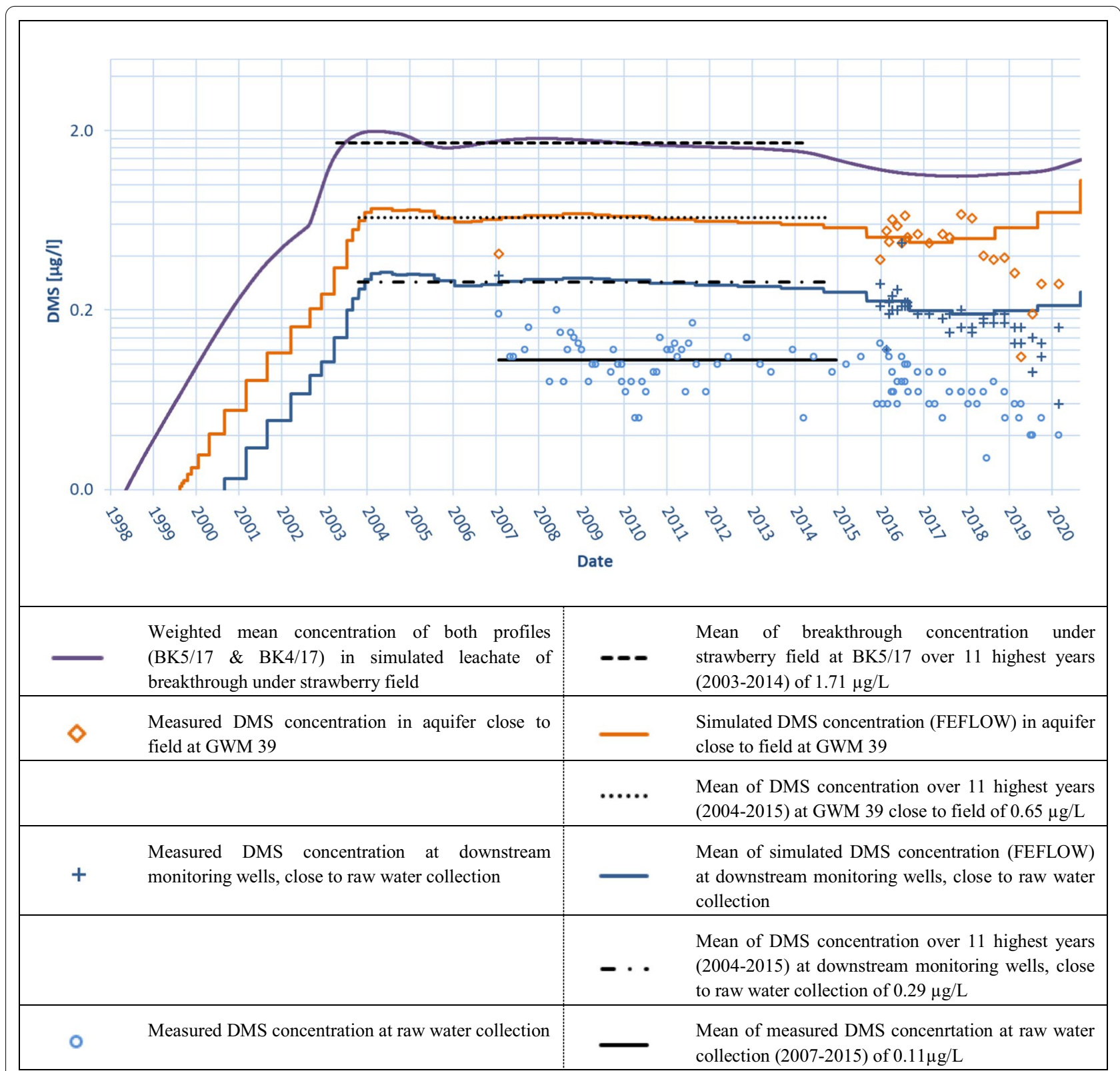

Fig. 27 Simulated vs. observed DMS concentrations from groundwater leaching to raw water collection

The stepwise leaching simulation of DMS from the PEARL/HYDRUS model combination is presented in Fig. 26. A mean concentration over a duration of 11 years, according to the use history, gives a relatively stable high concentration of $27 \mu \mathrm{g} / \mathrm{L}$ at $1 \mathrm{~m}$ depth. After 18-19 years, the breakthrough curve of DMS in the profile BK5/17 at $39.9 \mathrm{~m}$ depth reached the corresponding plateau stage with a DMS concentration in the leachate entering the groundwater aquifer amounting to approx. $1.7 \mu \mathrm{g} / \mathrm{L}$.
An additional simulation was performed using a standardized FOCUS scenario Hamburg, which is used in a regulatory context in Germany and other EU countries. A resulting conservative DMS PECgw of $33.8 \mu \mathrm{g} / \mathrm{L}$ at $1 \mathrm{~m}$ depth was calculated (Fig. 26).

\section{Transport in aquifer}

In Fig. 27, the transport of DMS from the leachate at the top of the groundwater table to the raw water collection system is shown in simulated and observed concentrations. The DMS plume, as simulated by FEFLOW, first 


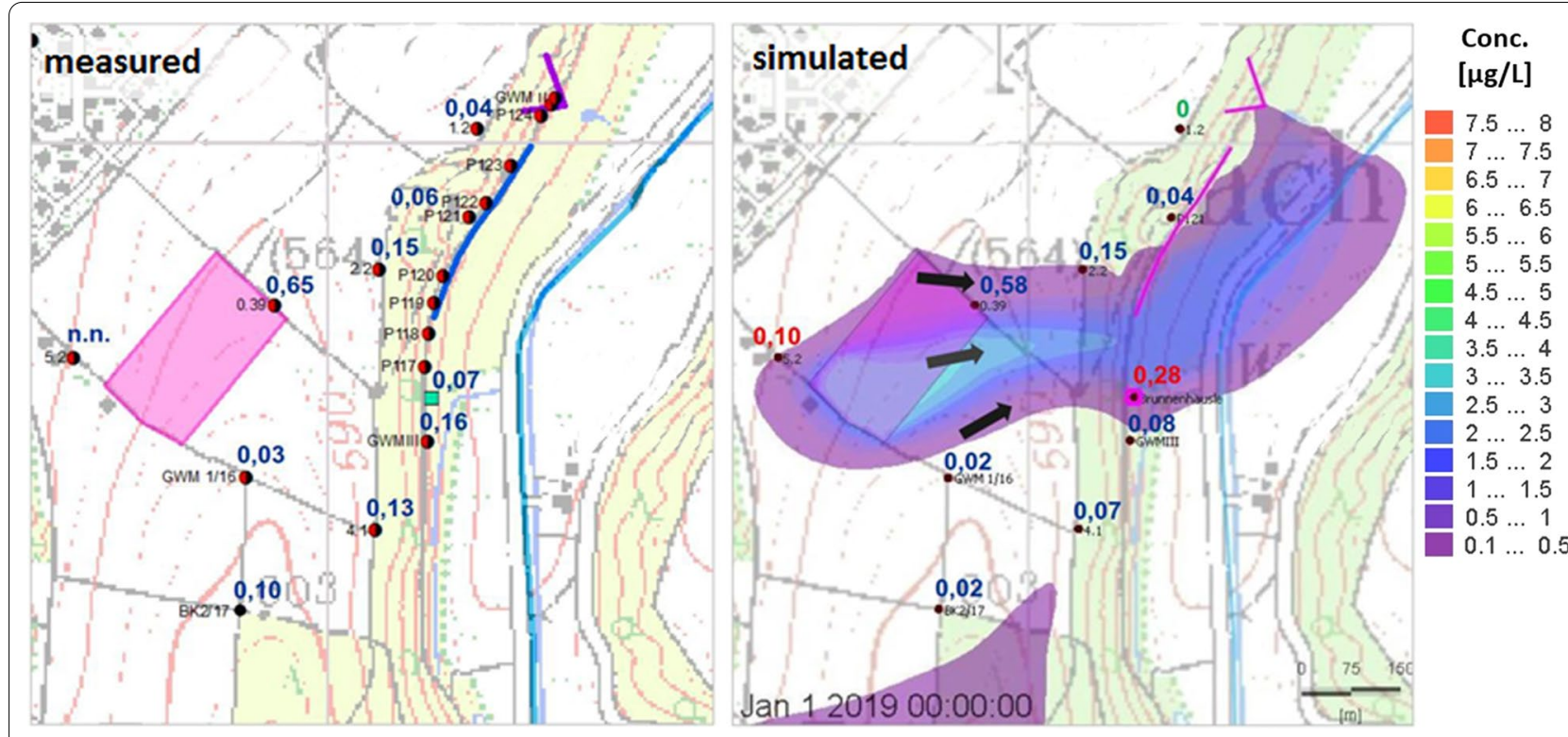

Fig. 28 Simulated vs. measured DMS concentrations in the transportation plume from strawberry field to raw water collection (based on unpublished expert report [29])

passes the monitoring well GWM 39, which is located downstream, directly next to the field. A relatively stationary phase of 11 years is represented by a mean concentration of $0.65 \mu \mathrm{g} / \mathrm{L}$. The first data point of measured DMS concentrations was generated in 2007. After a 9-year data gap, the measured data points were then generated continuously from 2016 onwards. At this monitoring point, simulated and observed DMS concentrations match visually well, and the simulation can be considered reliable.

Compared to the available monitoring data from two monitoring wells located downstream, close to the raw water collection system, the simulation also matches well (Fig. 28). The transport plume is simulated to move mainly between the two monitoring wells GWM 2.2 and GWM III. Therefore, it is unlikely to that the highest concentration will be measured at the sampling points on the plume fringes. The mean concentration from both monitoring wells over 11 years amounts to $0.29 \mu \mathrm{g} / \mathrm{L}$.

As reasoned in "Aquifer monitoring" of Catchment III under "Methods" section, the DMS concentration in raw water from this collection system likely represents the final attenuation of DMS concentration from the area of entry to the raw water used by the local water supplier. This raw water is not actively abstracted there by pumping. Therefore, it is suitable for use in this assessment. Otherwise, additional artificial dilution caused by a possible 'pumping funnel' could have biased the result. Only water, which would be running out at the side of the valley into the stream permanently anyway, is collected by the water supplier.

No major delay of the DMS concentration due to transport from the unsaturated zone into the aquifer and further down to the raw water collection exists at this site [29]. Therefore, only minor delayed concentration ranges, which largely intersect by time, can be compared. The mean stationary stage (11 years) of highest DMS concentrations at downstream monitoring wells, close to raw water collection takes place in 2004 to 2015. However, DMS concentration in raw water had only be monitored since 2007. This means, the timeline of the stationary stage simulated for downstream monitoring wells, close to raw water collection intersects with the measured concentration in raw water only from 2007 to 2015. Therefore, the mean stationary concentration in raw water was not calculated over the full 11 years, but only from 2007 to 2015. During this time, a mean concentration of $0.11 \mu \mathrm{g} / \mathrm{L}$ was observed in collected raw water.

\section{Final results on natural attenuation}

Results of a continuous attenuation of DMS concentrations in water with increasing distance to the treated areas are pointed out stepwise in Fig. 29. It reflects the DMS entry at each distance step over a period, which is related to the duration of use. For this, it delays according to individual transport duration.

In case of Catchment I, the most effective step of attenuation is marked by leaching from the vadose zone into the saturated zone with an attenuation factor of 7.1. From 


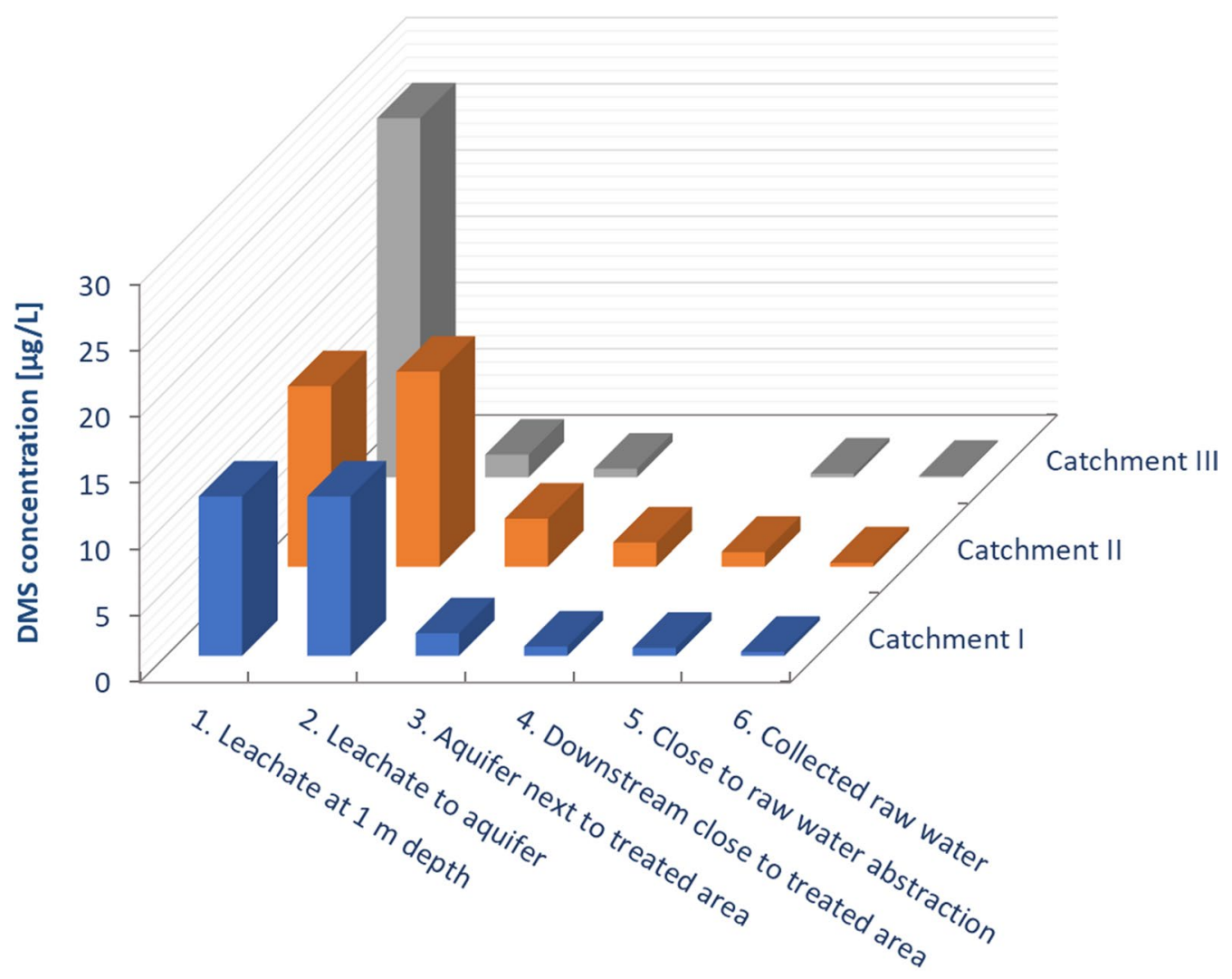

Attenuation Step

Fig. 29 Stepwise compared attenuation of DMS concentrations in leachate and groundwater over distance to treated areas

Table 5 Concentration of DMS in leachate and groundwater $[\mu \mathrm{g} / \mathrm{L}]$ and related attenuation factors

\begin{tabular}{|c|c|c|c|c|c|c|c|}
\hline \multicolumn{2}{|l|}{ Attenuation Step } & \multirow{2}{*}{$\begin{array}{l}\text { Catchment } \\
\text { I }\end{array}$} & \multirow{2}{*}{$\begin{array}{l}\text { Attenuation } \\
\text { factor }\end{array}$} & \multirow{2}{*}{$\begin{array}{l}\text { Catchment } \\
\text { II }\end{array}$} & \multirow{2}{*}{$\begin{array}{l}\text { Attenuation } \\
\text { factor } \\
-\end{array}$} & \multirow{2}{*}{$\begin{array}{l}\text { Catchment } \\
\text { III } \\
34\end{array}$} & \multirow{2}{*}{$\begin{array}{l}\text { Attenuation } \\
\text { factor }\end{array}$} \\
\hline 0 & $\begin{array}{l}\text { FOCUS scenario Hamburg at } 1 \mathrm{~m} \\
\text { depth }\end{array}$ & & & & & & \\
\hline 1 & Leachate at 1 m depth & 12 & - & 14 & - & 27 & - \\
\hline 2 & Leachate to aquifer & 12 & 1.0 & 15 & 0.9 & 1.7 & 16 \\
\hline 3 & Aquifer next to treated area & 1.7 & 7.1 & 3.6 & 4.1 & 0.7 & 2.6 \\
\hline 4 & Downstream, close to treated area & 0.7 & 2.4 & 1.8 & 2.0 & n.a. ${ }^{\text {a) }}$ & n.a. ${ }^{\text {a) }}$ \\
\hline 5 & Close to raw water abstraction & 0.6 & 1.2 & 1.1 & 1.6 & 0.3 & 2.2 \\
\hline 6 & Collected raw water & 0.3 & 2.0 & 0.3 & 3.7 & 0.1 & 2.6 \\
\hline \multicolumn{2}{|c|}{ Total attenuation (Step 1 to 5) "field-to-observation well" } & & 20 & & 12 & & 93 \\
\hline \multicolumn{2}{|c|}{$\begin{array}{l}\text { Overall attenuation (Step } 1 \text { to 6) "field-to-drinking water } \\
\text { well" }\end{array}$} & & 40 & & 45 & & 246 \\
\hline
\end{tabular}

${ }^{a}$ Not available

the treated orchard to the monitoring wells close to raw water abstraction, the DMS concentration is reduced, in total, by a factor of 20 at this site (see Table 5). At raw water abstraction, carried out from mixed water of the whole abstraction gallery, an overall attenuation by a factor of 40 was calculated.

Also, at the study site Catchment II, the transitioning from the vadose zone into the groundwater body is 
the leading process in the continuous attenuation, as the DMS concentration is reduced by a factor of 4.1. The total attenuation of DMS from the treated orchard to the monitoring wells located close to the water abstraction system is a factor of 12 (see Table 5). In the completely mixed raw water of the affected abstraction well, an overall attenuation by a factor of 45 can be supposed after calculation.

At the study site Catchment III, the main attenuation process was the long-term leaching of DMS through a relatively deep profile with dual-porosity parameterized layers with a factor of 16. From the treated strawberry field to the monitoring wells close to the raw water collection system, the DMS concentration is reduced, in total, by a factor of 93 (see Table 5). Down to raw water sampling, carried out from completely mixed water of the whole collection system, even an overall attenuation by a factor of approximately 246 can be assumed.

To allow for a comparison with an EU risk assessment of the reported DMS concentrations, the simulations results using the standardized FOCUS scenario Hamburg are also presented in Step 0 (see Table 5).

The results show that dilution as immediate consequence of breakthrough is the main driver of attenuation in the groundwater for the study sites Catchment I and Catchment II, which is confirmed by other studies, e.g., [37]. At Catchment III, the DMS concentration is mainly attenuated by the deep profile of the vadose zone. A longer time of residence in parts of the profile, with microbial degradation and more mixing with unloaded percolating water and finally greater dispersion could explain this result. These attenuation processes substantially reduce the level of DMS contaminations in drinking water.

\section{Discussion}

At the catchment area level, soil types, variability of the topsoil cover and depth to groundwater are significant factors affecting pesticide leaching into the aquifer [38]. While these factors were well-known at the treated field level during the time of use, on the catchment level in the context of long use histories several assumptions needed to be made for modeling (e.g., recharge, cropping after time of considered application). Since simulated concentrations had been calibrated and validated by observed data, these simulations were deemed reliable. Hence the simulated and/or measured results were considered comparable at a similar step of attenuation. It was supposed that further corrections of the attenuation (e.g., through background concentration) would not lead to substantially different overall results.
Background concentration data are not for all study sites available and continuously monitored. These concentrations can affect the attenuation factor significantly, especially in cases of lower concentrations close to the water abstraction systems. Since the concentrations at the first steps are much higher than any background concentration, and the main attenuation happens under the treated area, this imprecision of the results was considered acceptable.

For Catchment I, a more complex approach was performed. All results for this site could be validated with monitoring data.

For Catchment II, leaching was simulated, but not validated by measured data from the profile. Since the application scheme and the profile of the subsurface were less complex than at other study sites and the modeling parameters were well-known, the simulation was deemed reliable. Furthermore, no transport modeling was performed for this site. The simulation of groundwater movement in combination with the monitoring dataset was used instead. However, the first concentration monitoring data are highest and an even higher concentration in a given year could have therefore been possible (Fig. 21). Overall, the results show a slightly lower attenuation than at the other sites but are in line with these and seem plausible. This effect can be partly reasoned by the short distance of the treated area to the abstraction well. Results for this site are considered reliable. Moreover, this assumption is supported by another unpublished report [36] about raw water contamination at this site. There it is stated, that simulated raw water concentrations of DMS amounted to $0.30 \mu \mathrm{g} / \mathrm{L}$ in 2006 and $0.22 \mu \mathrm{g} / \mathrm{L}$ in 2007 and are in the same order of magnitude compared to the monitoring result at the abstraction system of $0.60 \mu \mathrm{g} / \mathrm{L}$ (2006) and $0.33 \mu \mathrm{g} / \mathrm{L}$ (2007).

The high total attenuation factor of 93 at Catchment III should be considered and assessed with restraint. The two monitoring wells in front of the raw water collection system are probably not directly located at the position of the maximum peak of the dispersion plume (Figs. 27 \& 28). However, it can be assumed that the collection system catches the entire DMS loading in groundwater at that location. Therefore, the calculated attenuation factor in collected raw water can be assessed as a reliable and realistic value. Nevertheless, explaining and predicting behavior at the small catchment scale is difficult, since a high variability exists in the subsurface of the treated field [38]. Notably, local fracturing of conglomerate layers is widely unknown.

The results are in line with other studies on attenuation and authority-approved assumptions. The following can be given as examples. 
In simulations, where polycyclic aromatic hydrocarbon (PAH) pollutant sources were considered in a same manner [39], a maximum dilution in the downstream of the plume by a factor of 30 to 50 was determined.

In the context of the European pesticide regulation process, it was demonstrated for fluazinam, that a dilution (based on $1 \mathrm{~m}$ leachate) in the aquifer by a factor of 50 would be reasonable. Additionally, a treatment on two-thirds of the area in the catchment with the active substance was considered a worst-case scenario [40]. According to the results found in the present study, a reduction of pesticide residue concentrations by a factor of 75 up to raw water abstraction does not seem to be a conservative assumption in some cases.

In the case of mesotrione-another pesticide assessed by a rapporteur member state in the frame of the European regulatory process, a range of dilution factors between 10 and 100 was considered reasonable [41]. Therefore, PECgw values calculated according to regulatory guidelines with a further applied attenuation by a factor of 10 can be assumed very conservative in this case.

Compared to results from other studies, the results found in the present study are considered reasonable.

In a recently published proposed guidance document on the conduct and interpretation of groundwater monitoring studies [16] seven different exposure assessment options (protection goals) for the evaluation of concentrations have been suggested. These differ by the location of the sampled groundwater and the contributing area, from the vadose zone just underneath a treated field (option 1) to drinking water abstraction wells (option 7). If the data of the present study were put into context of these exposure assessment goals, the results of studies in Catchment I and II would fit within exposure assessment: "shallow, between 1 and $10 \mathrm{~m}$ below ground surface" (option 4) and "residue concentration in raw water of an abstraction well, water not older than 50 years" (option 7). Catchment III would fit exposure assessment: "> $10 \mathrm{~m}$ below ground surface" (option 5) and option 7.

\section{Conclusions}

The results of this study provide an estimate of tracer substance concentrations on the general order of magnitude in different realistic cases at German sites. How far these results can be transferred to other sites in Europe or world-wide needs to be further investigated. The results of this study might not apply to sites with highly different climatic and hydrogeological conditions. However, due to the widespread different conditions at the study sites - not only climatic, but also in use history and subsurface conditions, such as depth to groundwater and soil properties -, a certain transferability to other regions may be possible.

Total attenuation by factors of 12 to 93 over time and distance from shallow pore water at areas of application down to monitoring wells close to raw water abstraction were calculated ("field-to-observation well"). If an additional attenuation step further down to collected raw water were included, overall attenuation by factors between 40 and 246 would be evaluated ("field-to-drinking water well").

The absence of crop rotation, which is generally the case for permanent crops (orchards) or long-term crops (strawberries), in combination with a long-term use of the same pesticide, leads to greater residue accumulation and higher leaching concentrations [42].

As required for pesticide registration approval, this study shows that processes of natural attenuation in soil and aquifer are highly effective in reducing pesticide concentrations. The use of a non-sorbing tracerlike pesticide metabolite in this study represents a worst-case situation for the determined attenuation factors and represents rather the lower limit of the possible range when compared to common pesticides and their metabolites. Pesticides and most of their metabolites typically sorb to soil and therefore are subjected to longer retention and associated more intense degradation and dilution. Therefore, the attenuation factors of the environmental concentrations (PECgw) below $1 \mathrm{~m}$ depth towards observation and drinking water abstraction wells of 12 and 40, respectively, determined in this study, can make a contribution to conservative regulatory risk assessments.

\section{Abbreviations}

$\mathrm{BBCH}$ : Biologische Bundesanstalt für Land- und Forstwirtschaft, Bundessortenamt und CHemische Industrie; DMS: N,N-Dimethylsulfamide; DYNSYSTEM: Dynamic input system; FEFLOW: Finite element modeling of flow; FOCUS: FOrum for the Co-ordination of pesticide fate models and their Use; HPLC-MS: High-performance liquid chromatography-mass spectrometry; IWW: Institut für Wasserchemie und Wassertechologie; MRM: Multiple reaction monitoring; LOQ: limit of quantification; NDMA: Nitrosamine N-nitrosodimethylamine; PEARL: Pesticide Emission Assessment for regional and local scales; PEC: Predicted environmental concentration; TZW: Technologiezentrum Wasser; USDA: States Department of Agriculture.

\section{Supplementary Information}

The online version contains supplementary material available at https://doi. org/10.1186/s12302-021-00490-2.

Additional file 1. Monitoring data.

\section{Acknowledgements}

The authors are grateful to the managers of the three drinking water catchment areas for providing the data and help explaining the processes in the water treatment plants. We also thank M. Himml, T. Oertel, B. Büchler, U. Spring, B. Starke and J. Weiß for the support with their expertise in the preparation of 
the expert reports. Moreover, we thank S. Mayer for providing data of analytical results of DMS and information about the raw water abstraction in Catchment II—Lower Rhine Bay. We would also like to thank Ms. T. Schnitzler for her commitment to sample analyses and the provision of measurement data for Catchment III; Upper Swabia—Southern Germany.

\section{Authors' contributions}

$\mathrm{MH}$ conducted analyses and interpretation of the data, calculation of parts of the environmental concentrations and writing of the manuscript. RS guided the evaluation, calculated parts of the environmental concentrations and was a major contributor to the manuscript. All authors read and approved the final manuscript.

\section{Funding}

The work on this manuscript and the evaluations shown therein were funded by Bayer AG.

\section{Availability of data and materials}

The detailed raw data that support the findings of this study are available from the water supplier of each study site, but restrictions apply to the availability of these data, which were used under license for the current study, and so are not publicly available.

Data are, however, available from the authors upon reasonable request and with permission of respective water supplier. The data that support the findings of this study are available upon request from the corresponding author RS. The data are not publicly available due to them containing information that could compromise research participant privacy/consent (Additional file 1).

\section{Declarations}

Ethics approval and consent to participate Not applicable.

\section{Consent for publication}

Not applicable.

\section{Competing interests}

The authors declare that they have no competing interests.RS is employed by Bayer AG, a manufacturer of plant protection products. MH works as consultant for Bayer and other clients.

\section{Author details}

${ }^{1}$ Rifcon GmbH, Efate Modelling, Goldbeckstraße 13, 69493 Hirschberg, Germany. ${ }^{2}$ Bayer AG, Division Crop Science, Alfred-Nobel-Str. 50, 40789 Monheim, Germany.

Received: 28 November 2020 Accepted: 27 March 2021

Published online: 10 May 2021

\section{References}

1. European Commission (2003) Guidance Document on the Assessment of the Relevance of Metabolites in Groundwater of Substances regulated under Council Directive 91/414/EC, Sanco/221/2000 -rev.10- final.

2. Schmidt CK, Brauch H-J (2008) N, N-dimethylsulfamide as precursor for $\mathrm{N}$-nitrosodimethylamine (NDMA) formation upon ozonation and its fate during drinking water treatment. Environ Sci Technol 42(17):6340-6346

3. Schmidt CK (2007) N,N-Dimethylsulfamid (DMS)_Ein Problemstoff mit zwei Gesichtern. Nachrichten aus dem Technologiezentrum Wasser Karlsruhe 22

4. European Food Safety Authority (2005) Conclusion regarding the peer review of the pesticide risk assessment of the active substance tolylfluanid. EFSA J 1-76

5. Fischer T, Haakh F, Kiefer J, Rogg J-M (2019) Belastung der Rohwasserressourcen für die Trinkwasserversorgung in Baden-Württemberg mit Rückständen von Pflanzenschutzmitteln. Grundwasserdatenbank Wasserversorgung, Karlsruhe, Germany
6. Anstötz S, Münch F, Jezussek M, Gilsbach W (2017) Welche Pflanzenschutzmittelrückstände spielen in bayerischem Trinkwasser eine Rolle? J Consum Protect Food Saf 12(S1):75-79

7. Barufke K-P, Berthold G, Börke P, Burucker G, Hilliges F, Jankowski A, Neumann P, Straus G, Wolter R, Wolters W, Haenel S (2019) Bericht zur Grundwasserbeschaffenheit—Pflanzenschutzmittel. Bund/Länder-Arbeitsgemeinschaft Wasser, Gotha

8. Bund/Länder-Arbeitsgemeinschaft Wasser (LAWA) (2019) Bericht zur Grundwasserbeschaffenheit_Pflanzenschutzmittel, Gotha, Germany, 2019.

9. National Research Council (2000) Natural attenuation for groundwater. The National Academies Press, Washington, DC

10. Rao P, Hornsby A, Jessup R (1985) Indices for ranking the potential for pesticide contamination of groundwater. In: Proceedings of the Soil and Crop Science Society of Florida, p 1-8.

11. Buttler T, Martinkovic W, Nesheim ON (2003) Factors influencing pesticide movement to ground water, University of Florida, Institute of Food and Agricultural Sciences, Florida

12. Leistra M, van der Linden AMA, Boesten JJTI, Tiktak A, van den Berg F (2001) PEARL model for pesticide behaviour and emissions in soil-plant systems : description of the processes in FOCUS PEARL v 1.1.1. Wageningen, Alterra

13. FOCUS (2006) Guidance document on estimating persistence and degradation kinetics from environmental fate studies on pesticides in EU Registration. Report of the Work Group on Degradation Kinetics, SANCO/10058/2005 version 2.0, p 434

14. FOCUS (2000) FOCUS groundwater scenarios in the EU plant protection product review process. Report of the FOCUS Groundwater Scenarios Workgroup, Sanco/321/2000 rev.2, 2000

15. Lee C, Schmidt C, Yoon J, von Gunten U (2007) Oxidation of N-nitrosodimethylamine (NDMA) precursors with ozone and chlorine dioxide: kinetics and effect on NDMA formation potential. Environ Sci Technol 41:2056-2063

16. Gimsing AL, Agert J, Baran N, Boivin A, Ferrari F, Gibson R, Hammond L, Hegler F, Jones RL, König W, Krueger J, van der Linden T, Liss D, Loiseau L, Massey A, Miles B, Monrozies L, Newcombe A, Poot A, Reeves GL, Reichenberger S, Rosenbom AE, Staudenmaier H, Sur R, Schwen A, Stemmer M, Tüting W, Ulrich U (2019) Conducting groundwater monitoring studies in Europe for pesticide active substances and their metabolites in the context of Regulation (EC) 1107/2009. J Consum Protect Food Saf 14(S1):1-93

17. Büchler B, Himml M (2013) 3D-Grundwasserströmungs- und tranportmodell WW2; Bericht zur DMS-Grundwasserstofftransportsimulation im Einzugsgebiet der Wassergewinnungsanlage [non-disclosed water treatment plant]. GEOBIT Ingenieur-Gesellschaft mbH, Aachen

18. Šimůnek J, van Genuchten MT, Šejna M (2006) The HYDRUS Software package for simulating two- and three-dimensional movement of water, heat, and multiple solutes in variably-saturated media, version 1.0, PC Progress, Prague, Czech Republic

19. Cooper HHJ, Jocob CE (1946) A generalized graphical method for evaluating formation constants and summarizing well-field history. Eos, Trans Am Geophys Union 27(4):526-534

20. Theis CV (1935) The relation between the lowering of the piezometric surface and the rate and duration of discharge of a well using groundwater storage. Eos, Trans Am Geophys Union 16(2):519-524

21. Himml M (2010) Auswertung von Pumpversuchen und Flowmetermessungen in Grundwassermessstellen des Einzugsgebietes der rechtsrheinischen Wassergewinnungsanlagen der [non-disclosed water treatment plant]. GEOBIT Ingenieur-Gesellschaft mbH, Aachen

22. Schaap MG, Leij FJ, van Genuchten MT (2001) Rosetta: a computer program for estimating soil hydraulic parameters with hierarchical pedotransfer functions. J Hydrol 251(3-4):163-176

23. Schaap M (2000) ROSETTA Version 1.2. U.S. Salinity Laboratory ARS-USDA, Riverside, USA. [Online]. http://www.ussl.ars.usda.gov.

24. Histock KM (2005) Hydrology: principles and practice, Malden, Oxford. Blackwell Publishing, Carlton

25. Spring U (2006) Grundwasserverhältnisse im Bereich [non-disclosed water treatment plant]. SIMULTEC AG, Zürich

26. Seibert K (2005) Ermittlung von Bodenkenndaten, Landwirtschaftliche Untersuchungs- und Forschungsanstalt Speyer (LUFA), Speyer

27. Lauer F, Botscheck J (2016) Description and classification of an agricultural test soil in [name of trial site], Kölner Bucht, Germany, according to Soil Taxonomy, Bonn 
28. Agri4Cast Data Portal (2019) Gridded agro-meteorological data in Europe, Joint Research Centre, European Commission, [Online]. https://agri4cast. jrc.ec.europa.eu/DataPortal/RequestDataResource.aspx?idResource= $7 \& 0=\& r=n$. Accessed 2019.

29. Weiß J, Starke B (2019) Grundwassermodellrechnungen [non-disclosed water treatment plant]; Berechnungen des Tolylfluanid-Methaboliten DMS. CDM Smith Consult GmbH, Alsbach

30. Trapp (2006) Hydrogeologisches Abschlussgutachten zur Abgrenzung eines Wasserschutzgebietes für die Quellwasserfassungen der [non-disclosed water treatment plant], Regierungspräsidium Freiburg, Landesamt für Geologie, Rohstoffe und Bergbau

31. Regierungspräsidium Freiburg, Landesamt für Geologie, Rohstoffe und Bergbau, "LGRB-Kartenviewer," [Online]. https://maps.lgrb-bw.de/. Accessed 29 May 2020.

32. Diersch H-JG (2014) FEFLOW : finite element modeling of flow, mass and heat transport in porous and fractured media. Springer, Heidelberg

33. Jaynes DB, Logsdon SD, Horton R (1995) Field method for measuring mobile/immobile water content and solute transfer rate coefficient. Soil Sci Soc Am J 59(2):352-356

34. Charnay M-P, Tuis S, Coquet $Y$, Barriuso E (2005) Spatial variability in 14C-herbicide degradation in surface and subsurface soils. Pest Manage Sci 61(9):845-855

35. Gelhar LW (1992) A critical review of data on field-scale dispersion in aquifers. Water Res Res 28(7):1955-1974

36. Sur R, Roepke B (2007) Dimethylsulfamide in drinking water abstracted from groundwater and surface water-comparison between modelling and monitoring data, Bayer AG, Monheim

37. Lasagna M, Debernardi L, Paolo C, De Luca DA (2013) Effect of the dilution process on the attenuation of contaminants in aquifers. Environ Earth Sci 70:2767-2784
38. Stuart ME, Gooddy DC, Hughes AG, Jackson CR (2006) A field and modeling study to determine pesticide occurrence in a public water supply in Northern England, UK. GroundW Monit Remediat 26(4):128-136

39. Grathwohl P, Maier U, Beyer C (2007) Aufkommen, Qualität und Verbleib mineralischer Abfälle-Anhang 9 Modellierung der Verdünnung/Abminderung von Stoffkonzentrationen im Grundwasser bei Stoffeinträgen aus Verwertungsmaßnahmen zur Unterstützung der Datenlage des UBA-Vorhabens „Umsetzung der Ergebnisse des BMBFVerbundvorhabens "Sickerwasserprognose" in konkrete Vorschläge zur Harmonisierung von Methoden" (UBA FE 20574 251) als ergänzende Grundlage zur Ausgestaltung der Bundesverwertungsverordnung, auf der Basis bisheriger Ergebnisse aus dem BMBF Forschungsvorhaben zur Sickerwasserprognose. Umweltbundesamt

40. Austria (Rapporteur Member State) (2019) Combined Draft Renewal Assessment Report prepare Commission Regulation (EU) N 1107/2009 on the active substance fluazinam

41. United Kingdom (Rapporteur Member State) (2015) Renewal assessment report (RAR) on the active substance mesotrione prepared by the rapporteur Member State, the United Kingdom, in the framework of Commission Implementing Regulation (EU) No 844/2012

42. Chilton P, Stuart M, Gooddy D, Williams R, Johnson A (2005) Pesticide fate and behaviour in the UK Chalk aquifer, and implications for groundwater quality. Q J Eng Geol Hydrogeol 38(1): 65-81, 2005.

\section{Publisher's Note}

Springer Nature remains neutral with regard to jurisdictional claims in published maps and institutional affiliations.

\section{Submit your manuscript to a SpringerOpen ${ }^{\circ}$ journal and benefit from:}

- Convenient online submission

- Rigorous peer review

- Open access: articles freely available online

- High visibility within the field

- Retaining the copyright to your article

Submit your next manuscript at $\boldsymbol{\nabla}$ springeropen.com 